\title{
A spatial and temporal map of $C$. elegans gene expression
}

\author{
W. Clay Spencer, ${ }^{1,7}$ Georg Zeller, ${ }^{2,3,7,8}$ Joseph D. Watson,, ${ }^{1,9}$ Stefan R. Henz, ${ }^{3}$ \\ Kathie L. Watkins, ${ }^{1}$ Rebecca D. McWhirter, ${ }^{1}$ Sarah Petersen, ${ }^{1}$ Vipin T. Sreedharan, ${ }^{2}$ \\ Christian Widmer, ${ }^{2}$ Jeanyoung Jo, ${ }^{4}$ Valerie Reinke, ${ }^{4}$ Lisa Petrella, ${ }^{5}$ Susan Strome, ${ }^{5}$ \\ Stephen E. Von Stetina, ${ }^{1,10}$ Menachem Katz, ${ }^{6}$ Shai Shaham, ${ }^{6}$ Gunnar Rätsch, ${ }^{2}$ \\ and David M. Miller III ${ }^{1,11}$ \\ ${ }^{1}$ Department of Cell and Developmental Biology, Vanderbilt University, Nashville, Tennessee 37232, USA; ${ }^{2}$ Friedrich Miescher \\ Laboratory of the Max Planck Society, 72076 Tübingen, Germany; ${ }^{3}$ Department of Molecular Biology, Max Planck Institute \\ for Developmental Biology, 72076 Tübingen, Germany; ${ }^{4}$ Department of Genetics, Yale University School of Medicine, New \\ Haven, Connecticut 06520, USA; ${ }^{5}$ Department of MCD Biology, University of California Santa Cruz, Santa Cruz, California \\ 95064, USA; ${ }^{6}$ Laboratory of Developmental Genetics, The Rockefeller University, New York, New York 10065, USA
}

\begin{abstract}
The $C$. elegans genome has been completely sequenced, and the developmental anatomy of this model organism is described at single-cell resolution. Here we utilize strategies that exploit this precisely defined architecture to link gene expression to cell type. We obtained RNAs from specific cells and from each developmental stage using tissue-specific promoters to mark cells for isolation by FACS or for mRNA extraction by the mRNA-tagging method. We then generated gene expression profiles of more than 30 different cells and developmental stages using tiling arrays. Machine-learning-based analysis detected transcripts corresponding to established gene models and revealed novel transcriptionally active regions (TARs) in noncoding domains that comprise at least $10 \%$ of the total $C$. elegans genome. Our results show that about $75 \%$ of transcripts with detectable expression are differentially expressed among developmental stages and across cell types. Examination of known tissue- and cell-specific transcripts validates these data sets and suggests that newly identified TARs may exercise cell-specific functions. Additionally, we used self-organizing maps to define groups of coregulated transcripts and applied regulatory element analysis to identify known transcription factor-and miRNA-binding sites, as well as novel motifs that likely function to control subsets of these genes. By using cell-specific, whole-genome profiling strategies, we have detected a large number of novel transcripts and produced high-resolution gene expression maps that provide a basis for establishing the roles of individual genes in cellular differentiation.
\end{abstract}

[Supplemental material is available for this article. The microarray data from this study have been submitted to the Gene Expression Omnibus (GEO) (http:// www.ncbi.nlm.nih.gov/geo) under accession nos. GSE23245-GSE23271, GSE23278GSE23287, GSE23769-GSE23770, and GSE25350-GSE25351.]

The generation of specific cell types depends on spatial and temporal control of gene expression. The nematode Caenorhabditis elegans has been widely utilized to address this question because of its simple body plan and fully sequenced genome (Hillier et al. 2005). Although composed of fewer than 1000 somatic cells, the tissues of C. elegans adults include cell types characteristic of all metazoans such as muscle, nerve, intestine, and skin (Hall and Altun 2008). Moreover, the developmental origin of each of these cells is fully described in a complete map of cell divisions from fertilized zygote to sexually mature adult (Sulston and Horvitz 1977; Sulston et al. 1983). The C. elegans genome sequence is also precisely defined and, at $\sim 100 \mathrm{Mb}$, is about one-thirtieth the size

\footnotetext{
${ }^{7}$ These authors contributed equally to this work.

Present addresses: ${ }^{8}$ European Molecular Biology Laboratory, 69117 Heidelberg, Germany; ${ }^{9}$ Department of Biochemistry \& Biophysics, The University of North Carolina at Chapel Hill, Chapel Hill, North Carolina, 27599, USA; ${ }^{10}$ Department of Molecular and Cellular Biology, Harvard University, Cambridge, Massachusetts 02138, USA. ${ }^{11}$ Corresponding author.

E-mail david.miller@vanderbilt.edu.

Article published online before print. Article, supplemental material, and publication date are at http://www.genome.org/cgi/doi/10.1101/gr.114595.110. Freely available online through the Genome Research Open Access option.
}

of the human genome (Hillier et al. 2005). However, with 20,168 predicted genes (http://wiki.wormbase.org/index.php/WS200), the C. elegans protein-coding genome is only slightly smaller than that of humans (http://www.sanger.ac.uk/PostGenomics/encode/ stats.html). Major classes of noncoding RNAs (ncRNAs) such as microRNAs (miRNAs) are also represented in C. elegans (Ruby et al. 2006; Kato et al. 2009). Thus, C. elegans provides a simple but representative model of development that depends on differential expression of a compact, well-described genome. Although C. elegans is completely sequenced, some predicted genes lack direct evidence of transcription, and other cryptic protein-coding genes and ncRNAs are likely to have been overlooked by gene prediction software (Hillier et al. 2009; Schweikert et al. 2009). In addition, the cell-specific expression patterns of the majority of C. elegans genes are unknown. Thus, the anatomy and development of the animal is defined at the resolution of the single cell, but a comparably precise atlas of gene expression is not currently available.

The goal of a comprehensive gene expression map has been achieved in part by analysis of promoter::GFP fusions for a broad array of protein coding genes (Dupuy et al. 2007; Hunt-Newbury et al. 2007; Murray et al. 2008; Liu et al. 2009). This methodology, however, is generally not quantitative and can be misleading if key 
regulatory elements are omitted from the reporter genes (HuntNewbury et al. 2007). We have adopted the alternative strategy of measuring native transcripts from a broad array of specific tissues and cell types. In addition, we used whole-genome tiling arrays in order to sample the entire nonrepetitive genome and therefore achieve an unbiased approach to transcript discovery. In addition to assigning gene expression to identified tissues and stages, our approach of analyzing different cell types and developmental periods also ensures detection of RNAs that may be selectively expressed during discrete temporal intervals or in limited numbers of cells. We accomplished this goal by utilizing recently developed methods for obtaining RNA from specific C. elegans cells (Roy et al. 2002; Zhang et al. 2002; Fox et al. 2005). Altogether, we sampled 13 embryonic cell types and 12 larval and adult tissues. We also produced tiling array data sets for whole-animal RNA isolated from seven different developmental stages. Additional profiling results were obtained from larval males and from the hermaphrodite gonad and soma. Thus, our data sets significantly enhance a growing body of tissue- and stage-specific gene expression for C. elegans (McKay et al. 2003; Pauli et al. 2006; Von Stetina et al. 2007; Meissner et al. 2009). Our results indicate that most protein coding genes (about 75\%) are differentially expressed among the stages and cell types that we sampled. In addition to providing evidence of extensive gene regulation, these results should also greatly aid genetic analysis by suggesting cell types or developmental stages in which highly expressed transcripts are likely to function. For example, our results provide the first comprehensive description of gene expression in $C$. elegans primordial germ cells and led to the discovery that proteins encoded by a subset of these genes are expressed well before their established roles in meiosis and oogenesis. To identify novel transcripts, we utilized a recently developed computational method for recognizing transcribed regions irrespective of their annotation status (Laubinger et al. 2008; Zeller et al. 2008). This approach revealed a large number of previously unannotated transcripts encoded by at least $10 \%$ of the C. elegans genome. These novel transcripts show striking cell specificity that may be indicative of tissue-specific functions. To facilitate the use of these data for future studies of gene function, we provide online resources for visualizing transcribed regions in a genome browser and for estimating relative gene expression levels across tissue types and developmental stages.

\section{Results}

Strategies for profiling specific cell types and developmental stages

Cell-specific RNA was obtained from GFPlabeled embryonic cells isolated by FACS the bottom. and from larval cells by use of the mRNA-tagging method (Fig. 1A,B, see also Supplemental Fig. S1). Altogether, we generated tiling array profiles from 25 different tissues, with each sample derived from one of five distinct developmental stages. The cell specificity of these data sets is reflected in the strong enrichment of native transcripts for the corresponding gene promoter used to mark each cell type for profiling (Supplemental Fig. S2). Corresponding reference data sets were collected from all cells for each of these developmental periods (Table 1; see Methods). We also generated an independent developmental series with total RNA isolated from whole animals at seven different ages (EE, LE, L1, L2, L3, L4, YA) (Table 1; Fig. 1C; Supplemental Table S1). An additional group of tiling array profiles was obtained from young adult hermaphrodite gonads, L4 hermaphrodite somatic cells, and L4 males. Because our samples were isolated by different methods, which could potentially result in biased representation, we used principal component analysis (PCA) to compare tiling array results (see below) obtained from specific cells and from whole animals. PCA shows that tiling array profiles obtained from whole embryos cluster with data sets generated from specific embryonic cells and
A

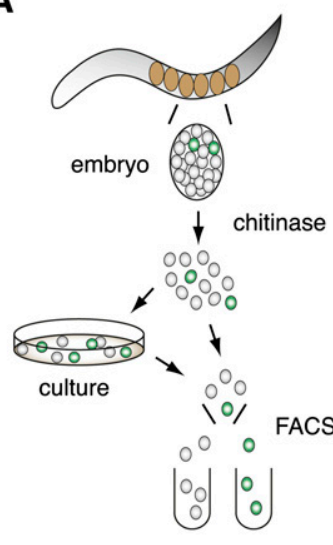

B
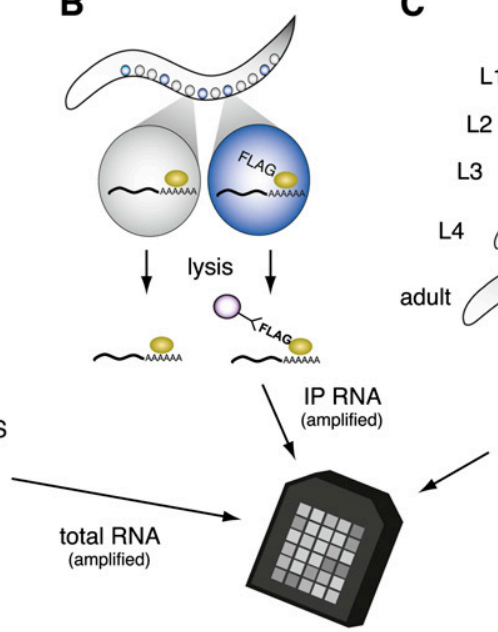

D

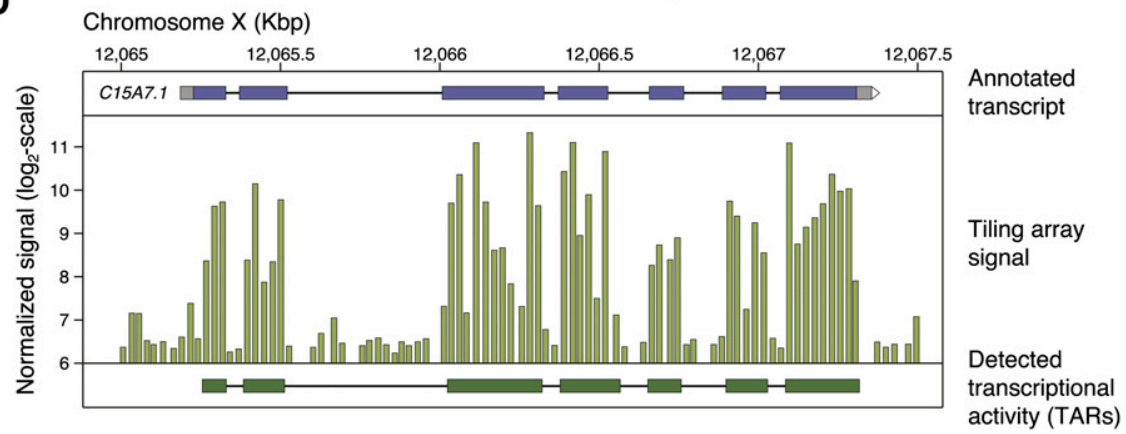

Figure 1. Strategies for generating tiling array data sets from specific $C$. elegans cells in embryos and larvae and from whole animals at defined developmental stages. $(A)$ In the MAPCeL (Micro-array Profiling of $C$. elegans Cells) method, embryos are isolated from gravid adults and blastomeres released by treatment with chitinase. Dissociated embryonic cells are either sorted immediately or cultured for 24 hrs before FACS. Total RNA is amplified for tiling array analysis. (B) The mRNA-tagging strategy was used to isolate RNA from specific larval and adult cells. The epitope-tagged (FLAG) polyA-binding protein (PAB-1) is expressed under the control of cell-specific promoters. The PAB-1:RNA complex is immunoprecipitated and RNA is amplified for tiling array analysis. (C) Total RNA is isolated from synchronized populations of embryonic, larval and adult animals for tiling array analysis. (D) Tiling array data (middle) is shown in a region around the annotated transcript C15A7.1 (top). Each vertical bar corresponds to the signal of one probe feature. A transcript identified by mSTAD using only the tiling array signal is shown at

\section{Genome Research www.genome.org}


Table 1. Samples used for expression profiling

\begin{tabular}{|c|c|c|c|}
\hline Name & Stage & Description & RNA \\
\hline \multicolumn{4}{|l|}{ Cell types and tissues } \\
\hline emb-0hr-ref & $\mathrm{EE}$ & all (EE) embryonic cells & $s$ total RNA \\
\hline emb-GLP & $\mathrm{EE}$ & germ-line precursors & total RNA \\
\hline emb-BAG & $\mathrm{EE}$ & BAG neurons & total RNA \\
\hline emb-reference & LE & all (LE) embryonic cells & $s$ total RNA \\
\hline emb-panneural & LE & all neurons & total RNA \\
\hline emb-AVA & LE & AVA neurons & total RNA \\
\hline emb-AVE & LE & AVE neurons & total RNA \\
\hline emb-A-class & LE & A-class motor neurons & total RNA \\
\hline emb-bwm & LE & body muscle & total RNA \\
\hline emb-coelomocytes & LE & coelomocytes & total RNA \\
\hline emb-dop & LE & dopaminergic neurons & total RNA \\
\hline emb-GABA & LE & $\begin{array}{l}\text { GABAergic motor } \\
\text { neurons }\end{array}$ & total RNA \\
\hline emb-hypodermis & LE & hypodermal cells & total RNA \\
\hline emb-intestine & LE & Intestine & total RNA \\
\hline emb-PhM & LE & pharyngeal muscle & total RNA \\
\hline L2-reference & L2 & all (L2) cells & poly $\mathrm{A}+$ /total RNA \\
\hline L2-panneural & L2 & all neurons & poly $\mathrm{A}+$ /total RNA \\
\hline L2-A-class & L2 & A-class motor neurons & poly $\mathrm{A}+$ /total RNA \\
\hline L2-bwm & L2 & body muscle & poly $\mathrm{A}+$ /total RNA \\
\hline L2-coelomocytes & L2 & Coelomocytes & poly $\mathrm{A}+$ /total RNA \\
\hline L2-excretory_cell & L2 & excretory cell & poly $\mathrm{A}+$ /total RNA \\
\hline L2-GABA_neurons & L2 & GABA neurons & poly A+/total RNA \\
\hline L2-glr & L2 & $\begin{array}{l}\text { glutamate receptor } \\
(g / r-1+) \text { neurons }\end{array}$ & poly $\mathrm{A}+$ /total RNA \\
\hline L2-intestine & L2 & intestine & poly $\mathrm{A}+$ /total RNA \\
\hline L3-L4-reference & L3-L4 & all (L3-L4) cells & poly $\mathrm{A}+$ /total RNA \\
\hline L3-L4-dop & L3-L4 & dopaminergic neurons & poly $\mathrm{A}+$ /total RNA \\
\hline L3-L4-hypodermis & L3-L4 & hypodermis & poly $\mathrm{A}+/$ total RNA \\
\hline L3-L4-PVD_OLL & L3-L4 & PVD and OLL neurons & poly $\mathrm{A}+$ /total RNA \\
\hline YA-ref & YA & all (YA) cells & poly $\mathrm{A}+$ /total RNA \\
\hline YA-CEPsh & YA & CEP sheath cells & poly $\mathrm{A}+$ /total RNA \\
\hline \multicolumn{4}{|l|}{ Whole animal } \\
\hline N2EE & $\mathrm{EE}$ & early embryos & total RNA \\
\hline N2LE & LE & late embryos & total RNA \\
\hline L1 & L1 & L1 animals & total RNA \\
\hline L2 & L2 & L2 animals & total RNA \\
\hline L3 & L3 & L3 animals & total RNA \\
\hline L4 & L4 & L4 animals & total RNA \\
\hline YA & YA & young adult animals & total RNA \\
\hline Soma-only & L4 & $\begin{array}{l}\text { L4 hermaphrodite } \\
\text { somatic cells only }\end{array}$ & total RNA \\
\hline Male & L4 & L4 males & total RNA \\
\hline Gonad & YA & hermaphrodite gonad & total RNA \\
\hline
\end{tabular}

EE indicates early embryo; LE, late embryo; L1, L1 larva; L2, L2 larva; L3L4, L3-L4 larvae; L4, L4 larva; and YA, young adult. For more details, see also Supplemental Table S1.

that larval and adult profiles are grouped with data sets obtained from specific postembryonic and young adult tissues (Supplemental Fig. S3). Correlation analysis comparing cell type data sets with developmental series data sets also confirms that expression estimates derived from cell types generally correlate well with the corresponding developmental stage data set generated from total RNA (Supplemental Fig. S4). Thus, a global analysis of our tiling array results suggests that cell-specific profiling preserves overall patterns of temporally regulated gene expression.

\section{Expression of annotated genes detected with tiling arrays}

To evaluate expression of annotated protein-coding genes, we created probe sets corresponding to the constitutive exons of individual gene models annotated in WormBase and summarized the intensity values for each gene (see Methods). We then identified transcripts that are detectable above background in each sample with a statistical test (see Methods). The union of results derived from all cell types and stages detected a total of 17,452 genes (Table 2). Because these results were obtained from multiple independent comparisons, we conservatively adjusted the false discovery rates (FDRs) to limit the potential accumulation of falsepositives (see Methods), which resulted in expression detected for 13,149 genes from the union of cell type-specific data sets and for 13,713 genes in at least one of the stage-specific data sets. When both groups of data sets were combined, we detected 14,279 expressed genes (Table 2).

Our initial analysis identified an average of 12,228 transcripts in samples derived from a specific cell type or tissue (Table 2). To provide a more accurate estimate of genes expressed in each tissue type, we adopted a simple transformation designed to exclude transcripts likely to originate with the minor fraction (3\%-20\%) of unmarked cells isolated by FACS (Supplemental Table S1) or from nonspecific RNA generated by the mRNA-tagging protocol (Von Stetina et al. 2007). Transcripts that are highly expressed in a specific tissue might also be detectable at lower levels in profiles derived from other cell types due to this background. Thus, as a conservative measure, we restricted the set of expressed genes for each cell type to transcripts with a higher level of expression measured for a given cell type than for the corresponding reference (i.e., the "average" cell) at the same stage. This approach effectively excluded, for example, the myo-3 body muscle-specific transcript (Okkema et al. 1993) from data sets derived from nonmuscle cell types while generally retaining "housekeeping" genes such as ribosomal proteins that are likely to be widely expressed in all tissues (Von Stetina et al. 2007). This analysis detected between 4572 and 7199 expressed genes in each of the 25 cell types profiled (5698 genes on average) (see Supplemental Fig. S5).

\section{Identification of transcriptionally active regions}

The high probe density (on average every $25 \mathrm{bp}$ ) of the tiling array made the nonrepetitive portion (about $85 \%$ ) of the genome accessible to de novo identification of transcripts in a way that is not biased by potentially incomplete annotations (for an illustration, see Fig. 1D). However, this comprehensive representation of the genome does not allow for optimized probe sequences and consequently results in large variability in hybridization affinity. Our pivotal normalization step thus aimed at reducing probe sequence bias. This correction also improved the signal-to-noise ratio (exon intensity over background) to an even larger extent than observed for another method that additionally exploits reference hybridization to genomic DNA (Fig. 2A; for details, see Methods) (Huber et al. 2006). For the segmentation of hybridization signals into intergenic regions, exons, and introns, we used a method called mSTAD (Laubinger et al. 2008; Zeller et al. 2008). Although mSTAD is trained on hybridization signals corresponding to known (mostly protein-coding) genes (see Methods), it afterward predicts transcripts regardless of their annotation status. We first assessed the cross-validation accuracy of these predictions relative to annotated protein-coding gene models (Fig. 2B). Generally, the sensitivity of these predictions for annotated exons improved with the expression level of the corresponding genes, while high precision (about $80 \%$ ) with respect to overlap with annotated exons was maintained across all expression levels (Fig. 2C). An additional evaluation of transcripts predicted by MSTAD in comparison to another tiling array-based method (Gerstein et al. 2010) further corroborated the conclusion that mSTAD accurately reconstructs expressed transcripts (Supplemental Figs. S6, S7; Supplemental Result SR4). 
Table 2. Gene models detected as expressed above background and with differential expression between cell types and references or between developmental stages

\begin{tabular}{|c|c|c|c|}
\hline & Cell types & $\begin{array}{l}\text { Developmental } \\
\text { stages }\end{array}$ & $\begin{array}{l}\text { Both data } \\
\text { sets }\end{array}$ \\
\hline Expressed genes ( $5 \%$ FDR) & 17,075 & 15,822 & $\begin{array}{l}17,452 \\
87.7 \%\end{array}$ \\
\hline Average no. of expressed genes per data set (5\% FDR) & $12,228^{a}$ & 12,252 & $\begin{array}{l}12,232 \\
61.4 \%\end{array}$ \\
\hline Expressed genes (stringent FDR) & 13,149 & 13,713 & $\begin{array}{l}14,279 \\
71.7 \%\end{array}$ \\
\hline Differentially expressed genes ( $5 \%$ FDR, FC $\geq 2$ ) & 10,598 & 9,552 & $\begin{array}{l}13,320 \\
66.9 \%\end{array}$ \\
\hline Differentially expressed genes (stringent $F D R, F C \geq 2$ ) & 7983 & 8606 & $\begin{array}{l}11,827 \\
59.4 \%\end{array}$ \\
\hline Differentially expressed genes ( $5 \%$ FDR, FC $\geq 5$ ) & 1596 & 1981 & $\begin{array}{c}3218 \\
16.2 \%\end{array}$ \\
\hline Differentially expressed genes (stringent FDR, FC $\geq 5$ ) & 1586 & 1974 & $\begin{array}{c}3206 \\
16.1 \%\end{array}$ \\
\hline Differentially expressed genes ( $5 \%$ FDR, FC $\geq 10$ ) & 270 & 620 & $\begin{array}{l}873 \\
4.4 \%\end{array}$ \\
\hline Differentially expressed genes (stringent FDR, FC $\geq 10$ ) & 270 & 620 & 873 \\
\hline
\end{tabular}

${ }^{a}$ On average per cell-type, 5698 genes with expression higher than in the reference sample were detected (see also Supplemental Fig. S5). This transformation is designed to remove transcripts that are highly expressed in other cell types but detected as background in a given cell-specific sample (see Results).

\section{TARs map to protein-coding genes and to intergenic domains}

From the transcriptionally active region (TAR) predictions of individual samples, we constructed nonredundant TARs (nrTARs) containing the union of nucleotides inclusive to a TAR in any of the samples analyzed ( 30 cell type and reference samples and seven developmental stages) (Table 1$)$. In total, $\sim 45 \mathrm{Mb}$ were covered by nrTARs, and the subset of expressed nrTARs (i.e., TARs that passed a statistical test for expression above background, see Methods) contained $\sim 40 \mathrm{Mb}$ (Supplemental Table S2). We next compared on an individual-nucleotide basis the overlap between known transcripts and nrTARs predicted de novo from the tiling array data. In a comparison to protein-coding gene models annotated in WormBase (Rogers et al. 2008), about $84 \%$ of nucleotides (i.e., $22,344 \mathrm{~kb} \pm 1127 \mathrm{~kb}$ ) in annotated exons (from more than $90 \%$ of gene models) were also detected in nrTARs (Fig. 2D). The subset of "expressed" nrTARs covered about $80 \%$ of nucleotides in annotated exons from more than $90 \%$ of gene models (Supplemental Table S3) and additionally contained $>18 \mathrm{Mb}$ (about $45 \%$ of expressed nrTARs) outside of exons for annotated proteincoding genes (Fig. 2D). A similar comparison between nrTARs and the modENCODE integrated transcript model defined by transcriptome sequencing of polyadenylated RNA (Hillier et al. 2009) and EST evidence from WormBase (Gerstein et al. 2010) detected $\sim 25 \mathrm{Mb}$ of overlapping exons or nrTARs corresponding to about $90 \%$ of nucleotides in exons of the integrated transcript model and about $57 \%$ of nucleotides in nrTARs (Fig. 2E). Nearly $41 \%$ of nucleotides within the expressed nrTARs were found outside of exons defined by the integrated transcript model (Fig. 2E). Taken together, most gene models (about 90\%) were supported by nrTARs, whereas a substantial fraction of nrTARs could not simply be attributed to known transcripts.

\section{Tiling array analysis detects $11 \mathrm{Mb}$ of novel TARs from intergenic regions}

We defined unannotated TARs as those that did not significantly overlap with exons of any coding gene, ncRNA, or pseudogene annotated in WormBase (Supplemental Fig. S8; Rogers et al. 2008). When we additionally required that TARs not overlap with any exons of the integrated transcript model, we obtained "novel TARs" (see Methods). In total, unannotated nrTARs covered $\sim 16 \mathrm{Mb}$ of the genome; about $90 \%$ were also novel (Fig. 2F). Expression above background in any sample could be confirmed by a statistical test (see Methods) for $\sim 11 \mathrm{Mb}$ of novel nrTARs (Fig. 2F; Supplemental Table S2; Supplemental Fig. S9A). These results suggest that our extensive profiling of cells and tissues as well as developmental stages revealed a significant fraction of the C. elegans transcriptome that went undetected by methods limited by analysis of polyadenylated transcripts or by sampling of fewer conditions (Rogers et al. 2008; Hillier et al. 2009). Our findings parallel results from a previous tiling array study that also detected abundant non-polyA+ transcription from intergenic regions (He et al. 2007). Although our transcript identification method was originally trained on annotated protein-coding genes, it is based purely on hybridization features (Laubinger et al. 2008; Zeller et al. 2008) and hence is expected to be capable of recognizing nonpolyadenylated as well as noncoding transcripts. We verified that TARs identified by mSTAD contain annotated ncRNAs, including snoRNAs, miRNAs, and pseudogenes (Supplemental Fig. S8; Supplemental Table S4). Moreover, on a per-nucleotide basis, almost $60 \%$ of the putative long ncRNAs $(>2.7 \mathrm{Mb}$ ) predicted by Lu et al. (2011) was contained in the set of novel nrTARs described here (Supplemental Fig. S11). However, less than 20\% of nucleotides from the novel nrTARs recognized by our approach were also predicted by Lu et al. (2011) (Supplemental Fig. S11). RT-PCR of a subset of these novel TARs confirmed expression (Fig. 3A,B).

\section{The majority of $C$. elegans genes are differentially expressed among cell types and developmental stages}

We profiled a broad panel of tissues and developmental stages with the idea that this approach could reveal the prevalence of potential gene regulatory mechanisms that might modulate transcript abundance among different cell types or developmental periods. To detect changes in gene expression during development, we performed all pairwise comparisons (total, 21 comparisons) of the seven tiling array data sets obtained from staged embryos (EE, LE), larvae (L1, L2, L3, L4) and young adults (YA) (see Methods). To detect transcripts that are differentially expressed between cell types, we compared each of the 25 cell-specific data sets to its corresponding reference sample (total, 25 comparisons) (Table 1). In both cases, these comparisons were designed to detect transcripts that are either significantly depleted or enriched (twofold or more, FDR $\leq 0.05$ ) (Fig. 4A). After correcting for multiple testing as above (Methods), this analysis produced conservative estimates of genes differentially expressed between stages (8606 on average) or between specific cell types and reference samples (7983) (Table 2; Supplemental Fig. S12). A combined, corrected threshold of FDR $<0.11 \%$ for all 46 comparisons yielded 11,827 differentially expressed genes among all stages and cell types tested (Table 2).

\section{Genome Research}


Although this stringent correction effectively reduced our estimate of the overall number of expressed transcripts from $88 \%$ to $72 \%$ of all C. elegans genes, the ratio of differentially expressed genes among detected genes in both cases is stable at about 75\% (Table 2; Supplemental Fig. S13). On the basis of these results, we conclude that transcripts for a majority of C. elegans genes are regulated to achieve different levels of expression during development and between specific types of cells.

To validate the enrichment of genes in tissues and cell types as detected here, we compared a select number of our enriched gene lists to similar, independently derived data sets. Comparison of enriched gene sets from this study for the L2 excretory cell, embryonic and L2 intestine, L2 body wall muscle, and YA gonad with comparable tissue-specific profiles generated by other groups produced highly significant overlaps (1.8- to 8.1-fold overrepresentations, all hypergeometric $P$-values $<1 \times 10^{-15}$ ) (see Supplemental Results SR1). These comparisons reinforce the validity of each data set, particularly since the earlier profiles were generated with a variety of methods including GFP reporter imaging and serial analysis of gene expression (SAGE) (see Supplemental Results SR1) and also may differ from our samples in developmental age. Lists of cell or tissue-enriched transcripts are included as supplemental data (http://www.vanderbilt.edu/wormdoc/ wormmap/) and should be useful for identifying genes with key roles in the corresponding cell type (see also Supplemental Results SR2). Examples of this application are provided for the embryonic germ cell precursors (see below) and for the larval excretory cell (Supplemental Result SR3).

\section{Specific genes are selectively enriched in certain cell types or tissues}

Among the genes that are enriched in a certain tissue, we further sought to distinguish genes that are selectively enriched in the given tissue relative to those with broadly elevated expression in many cell types. The information theoretic concept of Shannon entropy effectively allowed us to define this subset of selectively enriched genes by distinguishing patterns of broad and uniform expression (high entropy) from more restricted ones with a high degree of tissue specificity (low entropy) (see Methods; Schug et al. 2005). These lists of selectively enriched genes comprised about $20 \%-57 \%$ of all genes enriched in the corresponding tissue or cell type. Eighty-two percent of all genes selectively enriched in any cell type or tissue are specific to only one or two samples. Moreover, the overlap between tissues sampled at two time points is generally larger than between different tissues or cell types (Supplemental Fig.
S14). For example, the set of genes selectively enriched in embryonic dopaminergic neurons also shows elevated expression in larval dopaminergic neurons and comprises known dopaminergic genes, including the ETS transcription factor, ast-1, and its downstream targets the dopamine transporter dat-1 and dopamine biosynthetic enzymes cat-2 and cat-4. (Fig. 4B; Supplemental Result SR2; Flames and Hobert 2009).

We further defined the set of genes selectively enriched in any of the 13 neuronal samples, but not enriched in non-neuronal tissue. Strikingly, this combined neuron-selective data set is most strongly enriched for putative 7-transmembrane (7TM) domain G-protein-coupled receptor (GPCR)-like proteins (FDR $<5.2 \times 10^{-25}$ ) (Supplemental Fig. S15)

Our finding is consistent with earlier reports of selective expression of 7TM/GPCR genes in the C. elegans nervous system (Troemel et al. 1995; Chen et al. 2005). Cases of 7TM/GPCR genes
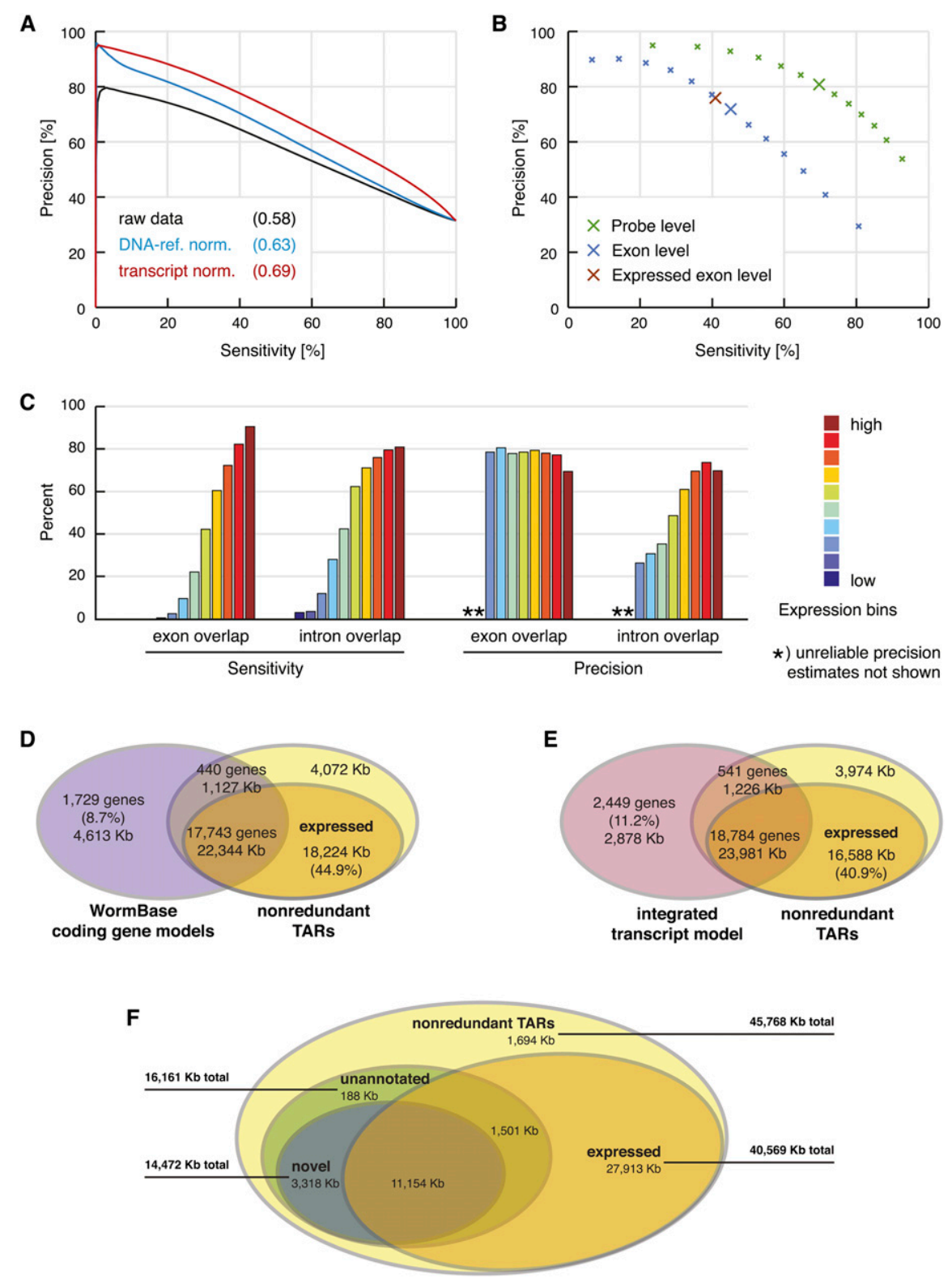

Figure 2. (Legend on next page) 
that are expressed in specific neurons are also evident in our tiling array results. For example, sra-32 and sra-36 are uniquely detected in the L2 larval stage A-class neuron data set (Fig. 4D). Of the 1512 predicted members of the 7TM/GPCR family, 314 (about 21\%) were not detected in any RNA-Seq-derived data set produced from whole animals (Hillier et al. 2009) for the modENCODE consortium (Gerstein et al. 2010). Among these are 66 family members that are detected in our tiling array assays (Supplemental File 1 7TM genes). Our findings provide an explanation for the relative lack of coverage of the 7TM/GPCR family in the RNA-Seq results and predict that transcripts encoded by other members of this large and diverse gene family could be detected by expanding our cellspecific profiling strategy to additional neuron types (Supplemental Fig. S16).

\section{Novel TARs are differentially expressed and many are selectively detected in certain cell types}

To quantitatively assess expression differences for TARs, in particular novel ones, probes contained within TARs from each cellspecific data set were compared to probes from the same region in the corresponding reference sample (see Table 1). This analysis revealed $\sim 5 \mathrm{Mb}$ of TARs with significant expression changes between cell types and references or between developmental stages at an FDR $\leq 0.05$ and twofold expression difference (see Methods; Supplemental Figs. S9B, S10). On average, 933 novel TARs are differentially expressed in a particular cell type in comparison to a reference sample of all cells at the corresponding developmental stage (Supplemental Figs. S9C, S12C). We used quantitative PCR (qPCR) to confirm that 10 of these differentially expressed novel TARs indeed show significant enrichment in the specific cell types initially identified in the comparison of tiling array results (Fig. 3C).

We next explored the extent to which novel TARs are selectively expressed with the goal of cataloging potentially rare transcripts that might be specifically detected in a limited subset of
A

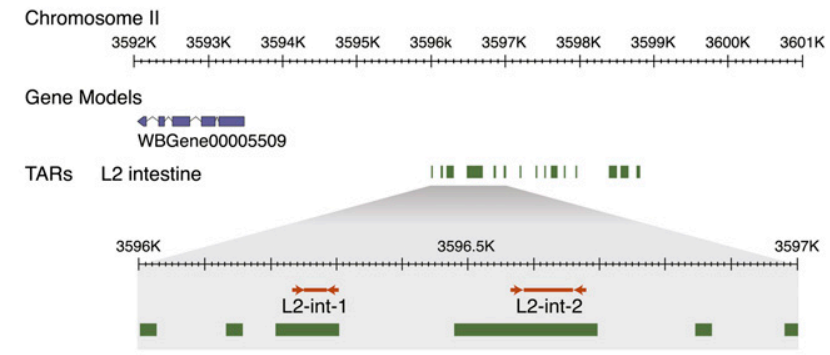

B

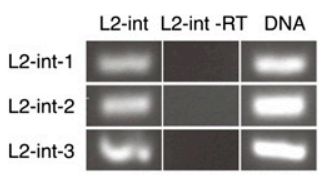

C

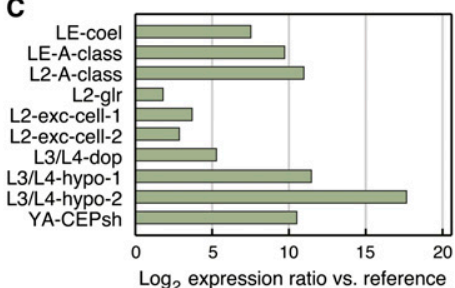

Figure 3. mSTAD detects TARs corresponding to protein-coding genes and to novel transcribed regions. (A) Novel TARs detected in larval L2 intestine. Enlarged region shows location of primers and predicted RT-PCR amplicon from two TARs, L2-int-1 and L2-int-2. (B) RT-PCR detects novel TARs expressed in specific cell types. TARs L2-int-1, 2, 3 are detected in RNA isolated from the larval L2 intestine (L2-int) but are not amplified from RNA in the absence of reverse transcriptase (L2-int-RT). (C) qPCR validates enrichment of novel TARs in specific cell types. $\log _{2}$ ratio of enrichment in specific tissue versus corresponding reference samples (Table 1).

cells or in a discrete developmental period. To investigate the expression patterns of TARs on a per-nucleotide basis, we tabulated the frequency at which a given base was detected as transcribed across cell types and stages. Approximately $15 \%$ of bases covered by exons of gene models annotated in WormBase are detected in all 25 cell types profiled (Fig. 4C). A larger fraction of bases derived from gene models (about 75\%), however, is expressed in at least one, but not all, of the cell types, and $11 \%$ is detected in no more than two cell types. For stages, we observed that $29 \%$ of bases from exons of annotated gene models is detected throughout development versus $8 \%$ expressed in no more than one developmental period (Supplemental Fig. S17). Bases corresponding to novel TARs that map to intergenic regions showed a stronger bias for cell- or stage-specific expression with more than 53\% detected in either one or two cell types but less than $1 \%(\sim 34 \mathrm{~kb})$ detected in all cell types (Fig. 4C). Bases located $>500$ nucleotides (nt) from a gene model (distal) comprised the majority (about $75 \%$ ) of novel transcribed intergenic nucleotides uniquely detected in one or two cell types or in a single stage (Fig. 4C; Supplemental Fig. S17). Given the average intron length of $344 \mathrm{nt}$ for $C$. elegans (Bradnam and Korf 2008), we suggest that these distal bases are more likely

\section{Genome Research} www.genome.org 
A

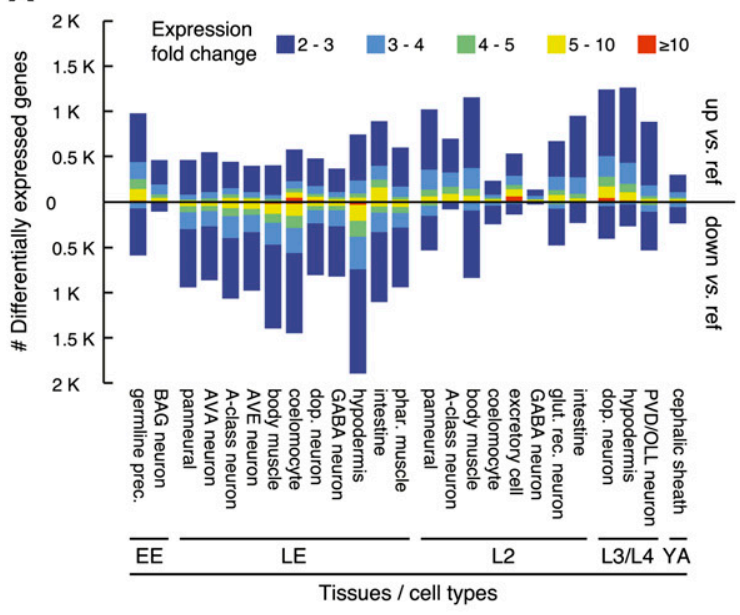

B

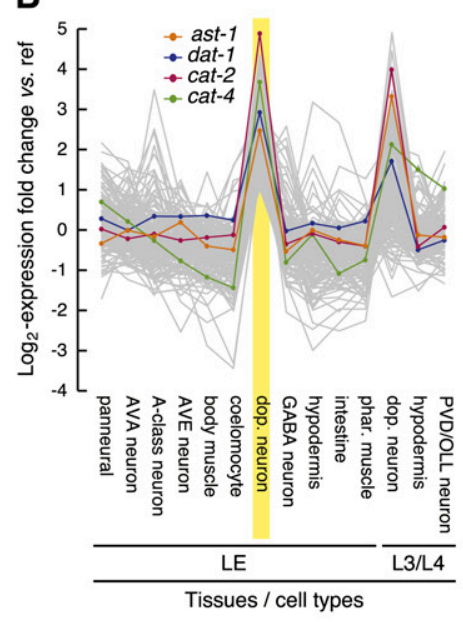

C

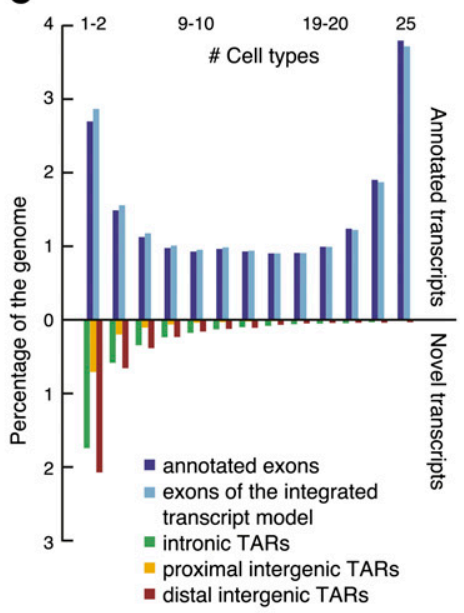

D

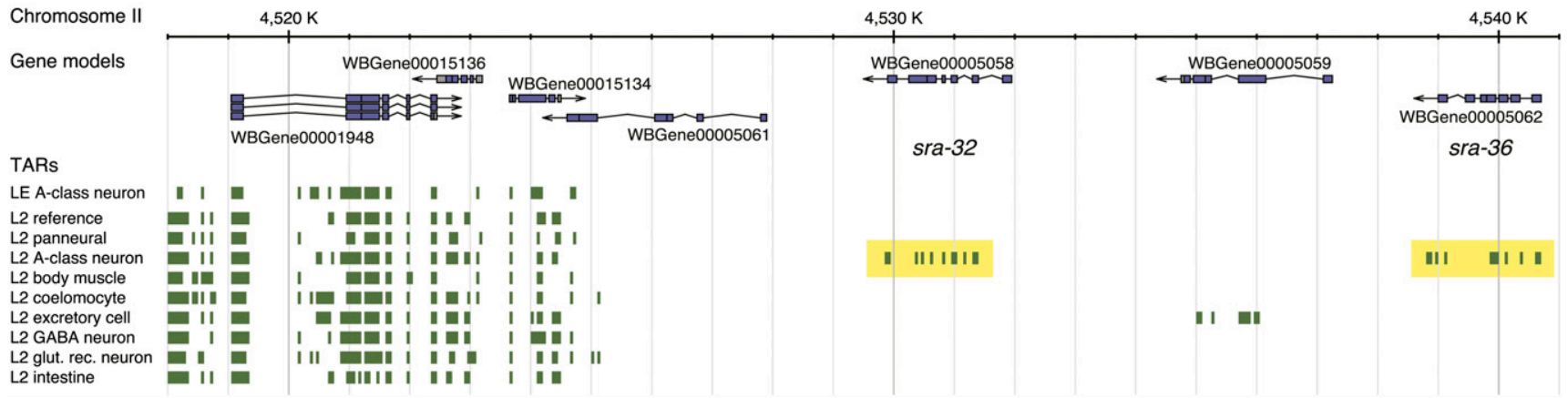

Figure 4. Transcripts enriched or depleted in certain cell types. (A) Genes differentially expressed between a given cell type and the corresponding reference sample (FDR $\leq 0.05$ ). Bars pointing up and down indicate the number of enriched and depleted genes, respectively, relative to reference.

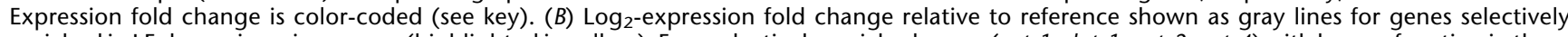
enriched in LE dopaminergic neurons (highlighted in yellow). Four selectively enriched genes (ast-1, dat-1, cat-2, cat-4) with known function in these neurons are plotted in color (see key). (C) Coverage of the genome by expressed transcripts at base-pair resolution. Nucleotides in nonredundant TARs (nrTARs) (for 25 cell-type samples) (Table 1) were binned according to the number of samples for which a TAR was detected at the given position. Bars pointing upward correspond to expressed TARs overlapping with exons of annotated coding genes and those defined by the integrated transcript model. Bars pointing downward correspond to nucleotides in expressed novel TARs (for definition, see main text) organized into subgroups according to their location relative to annotated protein coding gene models (see key). Intergenic positions were classified as proximal if within $500 \mathrm{bp}$ of any annotated gene and otherwise as distal. (D) 7TM genes are selectively expressed in a specific neuron. Two members (sra-32 and sra-36) of a tandem array (yellow highlights) of 7TM-encoding genes are selectively enriched in the A-type motor neuron data set derived from L2 larvae.

to correspond to new transcribed regions as opposed to exons belonging to existing gene models.

\section{Online resources for visualization and data access}

To facilitate further study of our tiling array-based expression data, we have made it accessible to the research community through two online visualization tools, both of which are linked from a project website (http://www.vanderbilt.edu/wormdoc/wormmap/). One of the utilities displays expression values across cell types and developmental stages for a user-defined subset of genes (http:// fml.mpg.de/raetsch/wormviz/tileviz.jsp; see also Supplemental Fig. S18). Additionally, a customized genome browser (http:// gbrowse.fml.mpg.de/cgi-bin/gbrowse/ce_WS199) visualizes TARs for all analyzed samples together with gene models and genomic features annotated in WormBase (see Supplemental Fig. S7; Rogers et al. 2008). Raw array data have been deposited at GEO (Barrett et al. 2009) (accession nos. GSE23245-GSE23271,
GSE23278-GSE23287, GSE23769-GSE23770, and GSE25350GSE25351), and supplemental data files are available for download from the project website (http://www.vanderbilt.edu/wormdoc/ wormmap/) and from modMine (http://intermine.modencode. org).

\section{Analysis of differentially expressed transcripts reveals cell-specific functions and clusters of co-regulated genes with candidate cis-acting motifs}

Our quantitative analysis has identified transcripts that are differentially expressed across a broad array of cell types and developmental stages. We expect that these results will provide a useful resource for future studies of cell-specific gene function and for identifying the regulatory elements that define spatial and temporal patterns of gene expression. Below we feature examples of these approaches in order to illustrate potential applications of these data sets. 
Cell-specific expression profiling of embryonic primordial germ cells reveals $\mathrm{X}$-chromosome silencing and early activation of meiosis and oogenesis genes

Two primordial germ cells, Z2 and Z3, are born from the $\mathrm{P} 4$ blastomere within $2 \mathrm{~h}$ of fertilization and ultimately give rise to all germ cells in the adult (Sulston et al. 1983). Z2 and Z3 are mitotically dormant and largely transcriptionally quiescent throughout embryogenesis, even as somatic cells rapidly proliferate and actively transcribe genes. Although some genes are known to be expressed in Z2/Z3 in older embryos (e.g., nos-2 and pgl-1) (Kawasaki et al. 1998, 2004; Subramaniam and Seydoux 1999), the full complement of genes actively transcribed in Z2/Z3 during this period has not been previously defined. Comparison of the $\mathrm{Z} 2 / \mathrm{Z} 3$ expression data set to a reference profile obtained from all embryonic cells (EE) (Table 1) identified 979 genes with significantly enriched (twofold or more, FDR $\leq 5 \%$ ) expression in Z2/Z3 (Supplemental File Z2/Z3 \#2). Because the germline reporter (Ppie-1::GFP:: PGL-1) (Table 1) used for marking Z2/Z3 for FACS shows expression in hypodermal cells of older embryos (data not shown; see also Supplemental Fig. S14), we removed 335 genes from the $\mathrm{Z} 2 / \mathrm{Z3}$ list that were also enriched in an independent profile of embryonic hypodermal cells (Table 1, see Supplemental Protocol SP13). We refer to the resultant list of 644 genes as the "core Z2/Z3" data set (Supplemental File Z2/Z3 \#2). This stringent treatment effectively excludes hypodermal genes from the core Z2/Z3 list but also eliminates other transcripts that are known to serve roles in germline development and are in fact expressed in Z2/Z3 (i.e., deps-1, ima-2, pgl-1, htp-3, cpg-2, daz-1) (Fig. 5, Supplemental Table S5).

Two observations indicate that the core $\mathrm{Z} 2 / \mathrm{Z} 3$ data set is strongly enriched for authentic Z2/Z3 transcripts. First, we detected significant overlap between the core Z2/Z3 data set and previously defined sets of transcripts produced in the adult germline (Reinke et al. 2000, 2004) and maternally loaded into embryos (397 of $644 \mathrm{Z} 2 / \mathrm{Z3}$ genes, $P<8 \times 10^{-72}$, hypergeometric test, see Methods) (Baugh et al. 2003). The core Z2/Z3 data set also significantly overlaps with a previously generated germline SAGE enriched gene data set (125 of $644 \mathrm{Z} 2 / \mathrm{Z3}$ genes, $P<1.62 \times 10^{-34}$ ) (Wang et al. 2009). Second, X-linked genes are as underrepresented in the core Z2/Z3 data set as they are in the adult germline (Fig. 5A; Supplemental File Z2/Z3 \#2; Reinke et al. 2004). This result provides the first evidence that the $X$ chromosomes are underexpressed in primordial germ cells, as has been previously documented in larval and adult germ cells. The specificity of this effect for germ cells is underscored by tiling array results obtained from adult hermaphrodite somatic cells ("soma only," Fig. 5A), which instead show overrepresentation of X-linked transcripts.
Strikingly, many genes expressed in Z2/Z3 have known roles in germ cell proliferation, meiosis, and oocyte differentiation (Supplemental Table S5; Supplemental Fig. S19) events that do not take place in the germline until larval and adult stages (Kimble and Crittenden 2005). In contrast, genes expressed during spermatogenesis are underrepresented in the Z2/Z3 data set (Supplemental File Z2/Z3 \#2). This observation suggests that the gene expression program for oocyte differentiation is activated in the primordial germ cells, whereas the program for spermatogenesis remains quiescent, even though spermatogenesis occurs prior to oogenesis in C. elegans hermaphrodites (Hubbard and Gerstein 2005; Shakes et al. 2009). Alternatively, many of the RNAs detected in this analysis could reflect the persistence of maternally provided transcripts in $\mathrm{Z} 2$ and Z3. To distinguish between maternal loading and zygotic transcription, we manually examined existing in situ hybridization images (NextDB; http://nematode.lab.nig.ac.jp) for genes in the core Z2/Z3 list (Supplemental Table S6). We found that 14 of 100 randomly selected genes in the core Z2/Z3 list show in situ signal in PGCs in embryos and/or L1s, compared with three of 100 randomly selected genes in the genome $(P=0.0047$, Fisher's exact test). Of the 14 genes from the core $\mathrm{Z} 2 / \mathrm{Z} 3$ list, 12 genes show new appearance of transcript signal in Z2/Z3 after a previously negative stage (i.e., $\mathrm{P} 4$ or an early stage of Z2/Z3 lacked signal) (prg-1, glh-1, ppw-2, lsl-1, pas-5, asb-1, iff-1, ucr-2.3, cpg-1, ife-3, rpl11.1, hil-4). Of those 12 genes, 10 show signal in $\mathrm{Z} 2 / \mathrm{Z} 3$ in newly hatched first stage larvae (L1s), and six show signal in embryos. Of

\section{Genome Research}


the three genes from the control list, all three show signal in Z2/Z3 in L1s (top-2, cra-1, mel-46), and none show signal in $\mathrm{Z} 2 / \mathrm{Z3}$ in embryos. These observations confirm that at least a subset of transcripts detected in the core Z2/Z3 data set are products of zygotic transcription in the primordial germ cells of embryos.

Transcription in Z2/Z3 of genes with protein products known to act later in development raised the question of whether zygotically expressed transcripts are translated in $\mathrm{Z} 2 / \mathrm{Z3}$. We addressed this possibility by immunostaining embryos with antibodies against several meiotic proteins. Strikingly, immunostaining for both HTP-3 and REC-8 (Pasierbek et al. 2001; Goodyer et al. 2008) is easily detected in embryonic Z2/Z3. Both proteins appear to be maternally loaded in early embryos, to diminish significantly by the P4 stage, and then to turn on in Z2/Z3 (Fig. 5B). Thus, at least some of the zygotically expressed transcripts are indeed translated in the primordial germ cells of embryos. This finding confirms the validity of our Z2/Z3 transcription profiling and provides a clear example of how these data can lead to new discoveries about germ cell biology.

\section{Self-organizing maps reveal cohorts of co-regulated genes during development and across specific cell types}

We used self-organizing maps (SOMs) to seek shared patterns of expression for transcripts derived from coding genes (see Methods). SOMs are a widely applied clustering technique that yields intuitive visualization of high-dimensional data sets, as, for example, generated with DNA microarrays (Jiang et al. 2001). SOMs are conceptually related to a technique previously proposed to construct a relational map of $C$. elegans gene expression (Kim et al. 2001). In the first instance, we fitted a SOM to the developmental stage data set (Fig. 6A) and identified eight regions that correspond to genes with shared patterns of either enrichment or depletion in specific developmental periods (Fig. 6B, see Methods). To demonstrate the variety of developmental expression patterns identified by this approach, we plotted the top $50 \%$ of best-fitting genes from each cluster (Fig. 6CF; for additional clusters, see Supplemental Fig. S20). Cluster 1 (CS1) contains genes with elevated expression in the embryo (Fig. 6B,C). Notable examples from this group include the FoxA transcription factor, pha-4, the hunchback homolog, hbl-1, (Krause et al. 1997) and the helix-loop-helix transcription factors (bHLH) hlh-2 and hlh3 , for which independent studies have detected peak expression in the embryo (Azzaria et al. 1996; Krause et al. 1997; Fay et al. 1999). Cluster 5 (CS5) contains genes with elevated expression in embryonic stages and in the adult (Fig. 6B,E). Strikingly similar protein and transcript levels have been previously observed for a member of this group, the FLYWCH transcription factor flh-1, which blocks expression of specific miRNA genes during embryogenesis (Ow et al. 2008).

We applied a similar SOM clustering procedure to the cell type-specific data sets in order to delineate genes that are coregulated in different tissues (Fig. 7A; Supplemental Fig. S21; see Methods). Because these cell types were sampled across a series of developmental stages, we also expected this approach to detect genes with temporally correlated expression. Figure 7A depicts the resultant regional clusters superimposed on the SOM. Clusters showing stage-specific expression include C1 (Fig. 7B), which features genes that are highly expressed in all postembryonic cell types and C7 (Fig. 7D), which is biased for genes expressed in late embryos and especially in neurons. C8 is dominated by genes that are highly expressed in neurons but are depleted or show weak expression in most other cell types (Fig. 7E). Examples of genes in this group include ric-4 (snap-25), a synaptic vesicle component that facilitates neurotransmitter release and is known to be exclusively expressed in neurons (Hwang and Lee 2003), and acy-1 

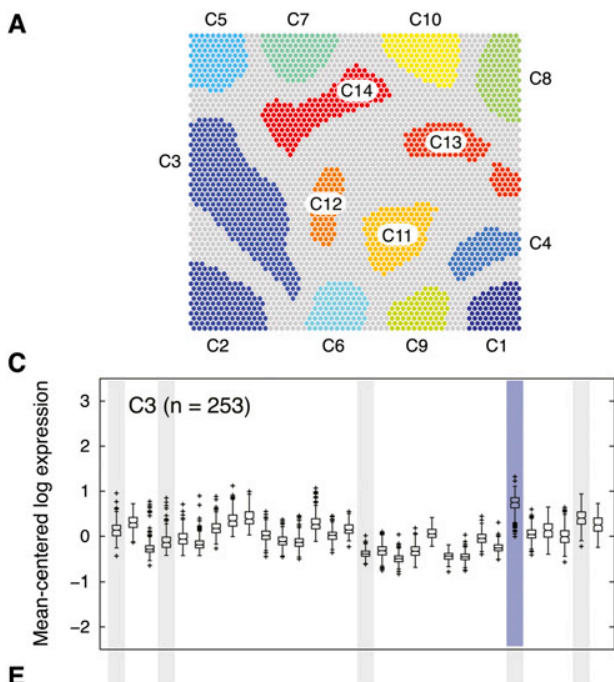

E

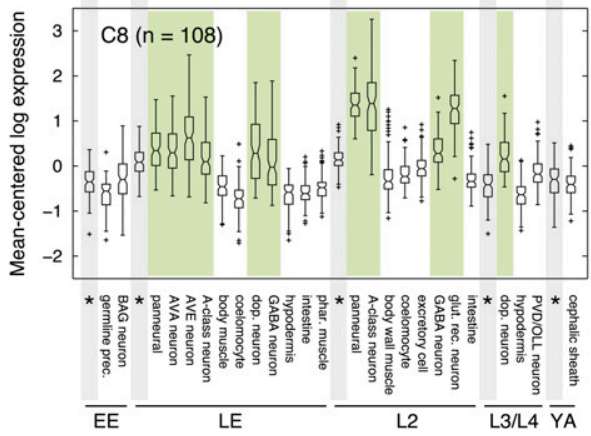

B

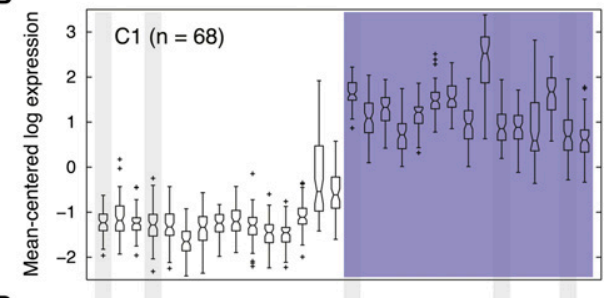

D

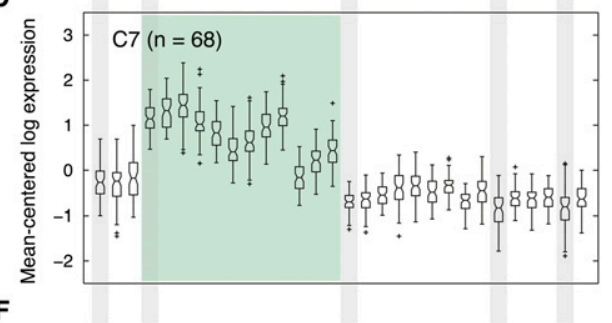

$\mathbf{F}$

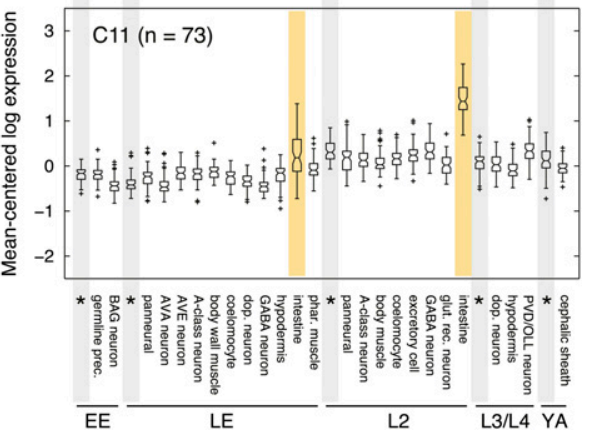

Figure 7. SOM clustering of tissue- and cell-type data. (A) Regions in the SOM for cell-type data as defined by $k$-means clustering. (B- $F$ ) Expression patterns of genes from selected clusters in the SOM. Cell types are indicated at bottom, and reference samples are shaded in gray. Box plots were generated from the mean-centered $\log _{2}$-expression values of prototypical genes for a given cell type with horizontal lines indicating the median, boxes delineating the interquartile range, and whiskers extending to the most extreme values within 1.5 times the median-quartile range; outliers are depicted as black crosses. Some of the SOM clusters correspond to peaked expression in a subset of cell types and/or developmental stages: (B) higher expression in larval stages and YA compared with embryo with a prominent peak for intestine, $(C)$ elevated expression in L3/L4 reference, (D) high expression in LE neurons, $(E)$ most neurons, and $(F)$ intestine (for SOM component planes and additional clusters, see Supplemental Figs. S22 and S23).

(adenylate cyclase), a key regulator of neuron-dependent behavior (Reynolds et al. 2005). Several clusters detect highly expressed intestinal genes including C1 (post-embryonic cell types and larval intestine) (Fig. 7B) and C11 (embryonic and larval intestine) (Fig. 7F; for additional examples, see Supplemental Fig. S22).

DNA sequence motifs associated with cell-specific and developmentally regulated gene expression

Because each SOM cluster includes genes with similar patterns of expression, we searched for instances in which genes in a specific cluster share common DNA sequence motifs through which transacting factors might coordinate their expression. To explore this possibility, we applied the FIRE motif analysis program to the SOM clusters (Elemento et al. 2007). FIRE uses mutual information between the presence or absence of a short nucleotide sequence and the occurrence of a gene in a particular expression cluster to identify overrepresented motifs. FIRE produces optimized motifs and links the results to motifs that are available in public databases.

FIRE identified 20 upstream promoter motifs and nine overrepresented 3' UTR sequences in genes contained in the SOM clusters derived from developmental stages (Figs. 6, 8A; Supplemental Figs. S23, S24). A canonical EBox and bHLH binding site is detected in cluster CS1, which, as noted above, includes transcription factors HLH-2 and HLH-3 (Thellmann et al. 2003). The overrepresentation of GATA-like transcription factor binding sites in four clusters (CS4, CS5, CS6, CS7) is likely indicative of the broad roles of GATA factors in multiple developmental pathways in C. elegans, including endodermal and hypodermal cell fate determination and differentiation, germline gene regulation, and aging (Koh and Rothman 2001; McGhee et al. 2007; Budovskaya et al. 2008; del Castillo-Olivares et al. 2009). The second highestranking motif corresponds to a GC-rich sequence that has been previously identified by computational analysis of germline expressed genes (Li et al. 2010). This motif is also similar to a putative transcriptional activation site for the E2F homolog, EFL-1, that promotes gene expression in the germline (Chi and Reinke 2006). Detection of these GATA and E2F sites in cluster CS5 is consistent with our finding that genes which contain these $5^{\prime}$ sites and which are enriched in germline precursor (GLP) cells (Supplemental File $\mathrm{Z2} / \mathrm{Z3}$ \#2) are also overrepresented in this cluster (23 GLP genes with the GATA site are 1.6-fold overrepresented, $P<0.017 ; 40$ GLP genes with the E2F site are 1.8-fold overrepresented, $P<2.74 \times 10^{-4}$ ). These results validate our approach and suggest that other motifs revealed by this strategy may also correspond to binding sites for transcription factors that regulate developmental gene expression.

\section{Genome Research}


A

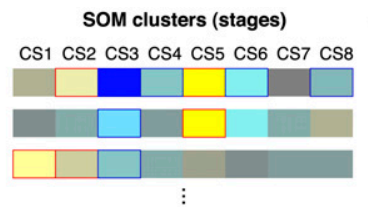

B

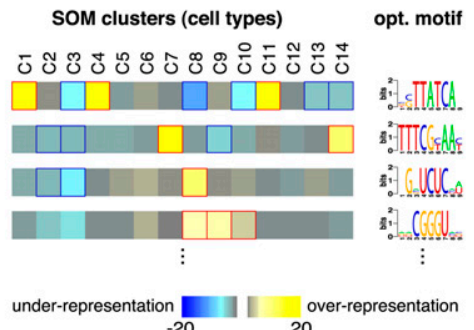

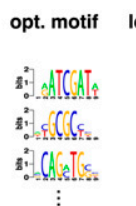

location
$5^{\prime}$
$5^{\prime}$
$5^{\prime}$
$\vdots$

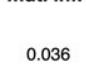

0.035

0.010

$\vdots$

\section{$5^{\prime}$}$$
5^{\prime}
$$

3'UTR

3'UTR$$
\text { mut. in }
$$

0.046

0.033

0.012

0.011 motif name

Homez, GATA2, CDP_CR3+HD ..

RSC3, E2F3_1, E2F2_1

E47, MyoD, $\mathrm{Sn} \ldots$

Figure 8. Selected regulatory elements discovered in stage and cell-type expression clusters. FIRE analysis identifies motifs over- and underrepresented in developmental profile clusters $(A)$ and cell-type profile clusters $(B)$. Complete results are shown in Supplemental Figure S23. A heat map indicates whether each motif is overrepresented (yellow) or underrepresented (blue) in each cluster. Motifs are arranged in rows and clusters in columns. Significant overrepresentation is indicated by red box outlines and underrepresentation is indicated by blue outlines $(P \leq 0.05$, Bonferroni-corrected). The optimized motif logo, location of the motif ( $5^{\prime}$ upstream promoter or $3^{\prime}$ UTR), mutual information with the genes in the cluster, and matching transcription factors and miRNAs listed in public data bases for indicated motifs are shown alongside the heat map.

For SOM clusters derived from cell-specific profiles (Fig. 8B), FIRE identified 45 overrepresented sequences including 35 upstream motifs and 10 RNA sequences that map to 3' UTR domains (Fig. 8B; Supplemental Figs. S23, S24). As noted above for the SOM clusters derived from developmental stages, the highest scoring motif matches a GATA transcription factor-binding site. In C. elegans, the elt-2 GATA transcription factor is known to interact with this sequence to drive expression of intestine-specific genes (McGhee et al. 2009). Our results also reflect this role; the GATA motif is overrepresented in cluster $\mathrm{C} 11$, which contains transcripts enriched in the embryonic and larval intestine profiles (Figs. 7F, $8 \mathrm{~B})$, and in $\mathrm{C} 1$ and $\mathrm{C} 4$, both of which show peak expression in larval intestine (Fig. 7B, 8B; Supplemental Fig. S22). The accurate identification of the GATA factor-binding site by the FIRE algorithm suggests that other motifs associated with specific SOM clusters may also correspond to specific transcription factor binding sites. An interesting example includes the sequence TTTCG[TC]AA[CT] (Fig. 8B), which is overrepresented in genes enriched in embryonic neurons in cluster C7 (Fig. 7D) and also reciprocally depleted in genes that are underexpressed in embryonic neurons in cluster C5 (Supplemental Fig. S22). This motif is bound by the vertebrate C/EBPalpha transcription factor (Grange et al. 1991), which has been shown to function with NeuroD to regulate neural gene expression (Sandelin et al. 2004; Calella et al. 2007). It will be interesting to determine whether C/EBP and NeuroD homologs exercise similar functions in C. elegans neural development.

FIRE also identified 3' UTR binding sites for two distinct groups of miRNA genes belonging to the mir-58 and mir-51 families (Fig. 8B; Supplemental Figs. S23, S24). Members of the mir-58 family (mir-58,-80,-81,-82) are abundantly expressed throughout development (Lim et al. 2003; Kato et al. 2009), but assays with promoter::GFP reporter genes have detected cell-specific patterns of expression (Martinez et al. 2008). For instance, mir-58 is expressed in a broad array of cell types, including the excretory canal, intestine, pharynx, and hypodermis, but is excluded from the nervous system (Isik et al. 2010). Emerging evidence indicates that transcript destabilization is the principle mechanism whereby
miRNAs down-regulate gene expression (Bagga et al. 2005; Guo et al. 2010). Thus, the absence of mir-58 expression in the nervous system predicts that neuronal transcripts carrying the mir-58 recognition sequence should escape mir-58-induced degradation. And, in fact, our result showing that the mir-58 sequence is overrepresented in neuron-enriched transcripts (cluster C8) (Figs. 7E, 8B) is consistent with this model. The motif for the mir-51 family (mir-51,-52,-53,-54, $-55,-56)$ is also overrepresented in $\mathrm{C} 8$ (Figs. 7E, 8B) and in SOM clusters C9 and C10 that are dominated by transcripts enriched in hypodermal cells and neurons (Supplemental Fig. S22). This pattern suggests that mir-51 family genes may have limited roles in regulating transcript levels in neurons and in the hypodermis. Conversely, the observation that the mir-58 and mir-51 motifs are significantly underrepresented in C2 and C3 is suggestive of strong regulation by these miRNAs in the tissues that contribute to this cluster. In considering this question, we noted that $\mathrm{C} 2$ and $\mathrm{C} 3$ include an expression peak for the L3/L4 reference sample (Fig. 7C). Because germline tissue is rapidly proliferating at this stage (Kimble 1981), we compared the genes in clusters C2 and C3 to separate tiling array profiles obtained from the adult hermaphrodite gonad and L4 males at L4 stage (see Supplemental Result SR5). These comparisons show a significant overlap, thereby indicating that $\mathrm{C} 2$ and $\mathrm{C} 3$ genes are largely expressed in the germline and specifically enriched for sperm expression. Thus, we speculate that members of the mir-58 and mir-51 gene families may have significant roles in modulating transcript levels in the germline. The mir-58 and mir-51 motifs were previously identified by FIRE analysis of an independent group of whole-animal microarray data sets from $C$. elegans (Elemento et al. 2007). Our results have now confirmed that each of these motifs is associated with a group of co-regulated genes and have also provided additional clues pointing to the specific cell types in which mir-51 and mir-58 might function.

\section{Discussion}

We have used whole-genome tiling arrays to profile RNA isolated from specific cells and developmental stages of C. elegans. Our strategy of sampling a variety of different cell types and developmental periods was designed to capture potentially rare or transiently expressed transcripts as well as to provide a detailed spatial and temporal map of gene expression.

To monitor expression of individual protein-coding genes, we derived intensity values from aggregated probe sequences corresponding to each annotated gene model. Our combined set of tiling array data from 25 different cell types and seven developmental stages (Fig. 1) detected about $90 \%$ of known protein coding genes (Table 2; Fig. 2; Supplemental Table S3).

In addition to detecting expressed genes, our analysis also revealed that about $75 \%$ of all detected genes show at least twofold, statistically significant differences in transcript levels between cell types or developmental stages (Table 2; Supplemental Fig. S13). To document this trend of widespread differential expression among 
cell types and throughout development, we tabulated the frequency of transcription of a given nucleotide across tissues and stages. This analysis revealed that whereas $15 \%$ of exonic sequence is detected in all of the cell types that we sampled, a larger fraction (60\%) shows more limited transcription with about $11 \%$ in no more than one or two cell types (Fig. 4C). Our results also indicate that coding sequence is dynamically expressed during development with about $8 \%$ of bases from exons uniquely detected in only one embryonic, larval or adult stage (Supplemental Fig. S17). As we extensively sampled the C. elegans nervous system, we investigated the subset of genes selectively expressed in neuronal tissue. Among these genes, we noted striking enrichment of members of the 7TM-GPCR family, which is known for highly specific expression in the nervous system (Chen et al. 2005). The restricted expression of 7TM-GPCR genes potentially explains why many members of this family still lack experimental support (Hillier et al. 2009; Schweikert et al. 2009). Our results, however, suggest that profiles of more cell types should confirm expression of additional annotated gene models (see Supplemental Fig. S16) or genes newly predicted from the genome sequence. Overall, our finding of widespread differential gene expression underscores the conclusion that most C. elegans genes are extensively regulated and points to the key role of differential gene expression in the determination of cell fates and developmental progression. In practice, our data on genes that are selectively enriched in a particular cell type or developmental period should be especially useful for identifying genes with cell- or stage-specific functions (Zhang et al. 2002; Colosimo et al. 2004; Blacque et al. 2005; Cinar et al. 2005; Touroutine et al. 2005; Von Stetina et al. 2007; McGhee et al. 2009; Chatzigeorgiou et al. 2010; Smith et al. 2010; Hallem et al. 2010). For example, our analysis of the transcripts enriched in the primordial germ cells (Z2/Z3) revealed two new features of germline development. First, compared to the autosomes, relatively few $\mathrm{X}$-linked genes are expressed in C. elegans primordial germ cells (Fig. 5A). This embryonic silencing of X-linked genes mirrors a similar effect in larval and adult germ cells (Reinke et al. 2004). Thus, except for a brief period of activation of X-linked genes in oocytes, the $\mathrm{X}$ chromosome is underexpressed throughout all stages of germ cell development. Second, Z2/Z3 express genes involved in meiosis and oogenesis, well in advance of when those processes actually occur. Moreover, at least some of those transcripts are translated into protein (Fig. 5B). This result raises the interesting question of whether those proteins serve additional nonmeiosis and nonoogenesis roles or instead whether primordial germ cells express many more of their repertoire of gene products than they need at that stage. Notably, the primordial germ cells of Drosophila and mice also express meiosis proteins, indicating that early expression of this protein class is conserved (Baltus et al. 2006; Mukai et al. 2006; Rogers et al. 2008). More detailed investigation of the individual genes expressed in $\mathrm{Z} 2 / \mathrm{Z} 3$ should provide a wealth of new information about the processes occurring in primordial germ cells, including mitotic quiescence and chromatin regulation. As one example, cyclin B is important for mitotic quiescence of germ cells in other systems such as Drosophila (Deshpande et al. 1999). Of the several orthologs of cyclin B in the C. elegans genome, only $c y b-2.2$ is enriched in the $\mathrm{Z} 2 / \mathrm{Z} 3$ data set, making it a candidate to mediate mitotic quiescence in $\mathrm{Z} 2 / \mathrm{Z3}$.

In addition to using our tiling array results to identify genes expressed in specific cell types or developmental periods, we also sought evidence for more complex patterns in which cohorts of genes might be similarly regulated across tissues or among different developmental stages. For this purpose, we used the unbiased strategy of SOMs to cluster coexpressed genes (Figs. 6, 7). This approach revealed, for example, a striking cluster with consistently elevated transcript levels in both embryonic and larval neurons that is largely composed of genes with established neuron-specific functions (Fig. 7E). Other clusters could reflect genes with common functions in a wide array of cell types during a particular developmental period (Fig. 7B,D). Thus, our approach has confirmed known groups of coregulated genes as well as suggested novel clusters that could point to previously unstudied biological roles for batteries of coexpressed genes. In addition to providing a direct read-out of cell-specific gene expression, our microarray data should also substantially enhance the accuracy of SVM-based strategies that rely on gold standard training sets for ab initio identification of cell-specific expression from whole-animal microarray data (Chikina et al. 2009). Motif analysis of the SOM results derived from our data sets identified highly overrepresented flanking sequences in genes belonging to specific clusters (Fig. 8; Supplemental Fig. S23). Each case could be indicative of a regulatory mechanism involving a shared trans-acting factor. For example, a consensus binding site for a GATA factor with a broad role in regulating intestine-specific genes in C. elegans (McGhee et al. 2009) was specifically overrepresented in SOM clusters defined by transcripts with high expression levels in tiling array data sets derived from intestinal cells (Fig. 8B). Overrepresented motifs in the 3' UTR regions include recognition sites for two large and highly expressed groups of closely related miRNAs, the mir-58 and mir-51 families (Fig. 8B). Our analysis of these results points to potential roles for both mir-58 and mir-51 in regulating transcript abundance in the germline, a suggestion consistent with the recent observation that the Drosophila ortholog of the mir-58 family, bantam, is required for germline stem cell fate (Yang et al. 2009).

Our tiling array results confirm expression of the vast majority (about 90\%) of C. elegans protein coding genes recently identified by RNA-Seq analysis (Supplemental Table S3; Hillier et al. 2009). Additionally, our machine-learning algorithm also identified a substantial number of TARs arising from intergenic regions (Fig. 2D-F). A conservative treatment of these data that uses a statistical test for expression above background leads to the estimate that $\sim 11 \mathrm{Mb}$ of intergenic sequence, or about $10 \%$ of the C. elegans genome, encodes novel RNAs that have not been previously annotated in WormBase or detected by RNA-Seq (Supplemental Table S2). One explanation for this difference is that we assayed total RNA from embryonic cells and developmental stages and that the poly-A+ pull-downs that we used for sampling postembryonic cell types (Fig. 1B) also include a significant nonpolyA+ fraction (Von Stetina et al. 2007). In contrast, recent RNASeq results for $C$. elegans were limited to purified poly-A+ RNA (Hillier et al. 2009). Because the known families of short ncRNAs were manually excluded from our list of intergenic RNAs, we propose that these transcripts define potentially new types of ncRNA. An independent analysis of $C$. elegans transcriptomics data that includes the tiling array results used in this work also reports a substantial number $(\sim 4.6 \mathrm{Mb})$ of putative ncRNAs from intergenic regions with a large overlap ( $>2.5 \mathrm{Mb}$ ) to our ncRNA predictions (Supplemental Fig. S11; Lu et al. 2011). Our analysis indicates that transcription of these novel TARs shows an even stronger bias for cell-specific expression than transcripts derived from protein coding genes (Fig. 4C). In this respect, our findings are similar to an earlier report that a majority of unannotated human transcripts are expressed in only one of the 11 different cell lines sampled (Birney et al. 2007). Although the extent of intergenic transcription from the mammalian genome is controversial (van Bakel et al. 2010), 
mounting evidence points to multifaceted roles for long intergenic ncRNAs (lincRNAs), including transcriptional control, imprinting, dosage compensation and maintenance, and remodeling of chromatin structure (Rinn et al. 2007; Hirota et al. 2008; Wilusz et al. 2009; Tsai et al. 2010). Nevertheless, in every case, definitive tests are required to establish specific functions for candidate regulatory ncRNAs. The tissue-specific patterns of ncRNA expression (Fig. 4C; Supplemental Fig. S12C) that we have revealed for C. elegans should provide a valuable guide to the likely focus of mutant phenotypes that perturb expression of specific ncRNAs (Mercer et al. 2008). We note, for example, that the recent discovery of an in vivo role for the lincRNA, Evf2 (also known as Dlx6os1), in neuronal differentiation hinged on prior knowledge of Evf2 expression in a specific brain region (Bond et al. 2009).

Although the tiling array results reported here should provide a useful resource for defining the roles of specific genes in cell fate and development, RNA-Seq data derived from these cell specific RNA samples would offer a more accurate representation of gene structure and substantially greater dynamic range for measuring differential gene expression. With the recent development of effective methods for excluding ribosomal RNA from sequencing templates (Armour et al. 2009; Albrecht et al. 2010), it should now be feasible to use RNA-Seq for a direct test of the ncRNA transcripts predicted by our tiling array results (W.C. Spencer and D.M. Miller, unpubl.). The fact that cell-specific tiling arrays detected predicted coding genes that were not touched by RNA-Seq analysis of $C$. elegans transcripts derived from the whole animal, also suggests that deep sequencing of RNA isolated from individual cell types could reveal additional protein-coding genes (see Supplemental Fig. S16).

\section{Methods}

\section{Sample production}

\section{Nematode culture}

C. elegans strains were maintained as described (Brenner 1974). We used N2 as the wild-type strain. Other strains used in this study are listed in Supplemental Table S1.

\section{Construction of cell-specific 3XFLAG::PAB-1 plasmids}

To express 3XFLAG-tagged PAB-1 in specific cell types, promoters were amplified and cloned into the pSV41(Pgateway::3XFLAG::PAB-1 + unc-119 minigene) plasmid using the Gateway cloning system (Invitrogen). Transgenics were obtained by microparticle bombardment or by microinjection (see Supplemental Protocols SP1-SP4).

\section{Isolation of cell-specific RNA by the mRNA-tagging method}

Cell-specific RNA was isolated from transgenics expressing 3XFLAG-tagged PAB-1 using the mRNA-tagging strategy (Roy et al. 2002) described by Von Stetina et al. (2007; see Supplemental Protocol SP5).

\section{Preparation and primary cell culture of embryonic cells and isolation of fluorescently labeled embryonic cells by FACS}

Embryonic cells were isolated by FACS as previously described (Christensen et al. 2002; Fox et al. 2005, 2007). Cell types were sorted to a fractional purity ranging from $80 \%-97 \%$ (Supplemental Table S1). RNA was extracted from sorted cells in TRIzol LS, treated with DNase I, and purified using the DNA-free RNA kit from Zymo Research (see Supplemental Protocols SP6-SP8).

\section{RNA amplification and microarray hybridization}

RNA from sorted cells and mRNA-tagging lines was amplified and labeled using the WT-Ovation Pico, WT-Ovation Exon, and Encore Biotin kits from NuGEN for application to C. elegans tiling arrays (Affymetrix). Pearson correlation coefficients between replicates were determined to confirm consistent microarray data quality (see Supplemental Protocols SP9, SP10).

\section{$R T-P C R$ and $q P C R$ to validate novel and differentially expressed transcripts}

Primers were designed to produce short amplicons (75-150 bp) using Batch-Primer3 (You et al. 2008). RT-PCR was performed using the same cDNA produced for microarray analysis for template and GoTaq polymerase (Promega). qPCR was performed using the same cDNA produced for microarray analysis for template and Sso-Fast Eva green reaction mix on a CFX96 real-time PCR machine (BioRad) (Fig. 3; see Supplemental Protocols SP11, SP12).

\section{Immunochemistry for Z2/Z3 protein expression}

Embryos were fixed using methanol/acetone (Strome and Wood 1983). Images were acquired with a Volocity spinning disk confocal system (Perkin-Elmer/Improvision) fitted on a Nikon Eclipse TE2000-E inverted microscope (Fig. 5B; for details, see Supplemental Protocol SP13).

\section{Computational analyses of tiling array data}

\section{Array annotation}

Tiling array features were mapped to the C. elegans genome and WormBase gene annotation (Rogers et al. 2008). Additionally repetitive tiling probes were flagged (see Supplemental Protocol SP14). Based on annotated protein-coding gene models, tiling probes were annotated into exonic, intronic, intergenic, and ambiguous categories.

\section{Normalization and transcript identification}

Raw tiling array data were normalized to correct for uneven background (Borevitz et al. 2003; Zeller et al. 2009), between-array variability with quantile normalization (Bolstad et al. 2003), and probe-sequence effects with transcript normalization (Zeller et al. 2008). We evaluated the extent to which normalizing for probe sequence effects improved subsequent transcript recognition in comparison to DNA reference normalization (Huber et al. 2006) on the basis of the above probe annotation (Fig. 2A). In this context, we defined sensitivity as the percentage of tiling probes with signal above a cutoff (true-positives, TP) among all annotated exon probes and undetected ones (false-negatives, $\mathrm{FN})$ : $\mathrm{Sn}=\mathrm{TP} /(\mathrm{TP}+$ FN). Precision was defined as the percentage of annotated exon probes (TP) among those with signal above the cutoff (including true- and false-positives, $\mathrm{FP}): \mathrm{Pr}=\mathrm{TP} /(\mathrm{TP}+\mathrm{FP})$. Varying the threshold parameter across the whole range of measured array intensities resulted in curves showing different trade-offs between precision and sensitivity (Fig. 2A; see Supplemental Protocol SP15).

For de novo identification of TARs from tiling array data, we employed mSTAD (margin-based segmentation of tiling array data), a machine-learning-based method (Laubinger et al. 2008; Zeller et al. 2008). Its internal parameters were trained on hybridization patterns and tiling probe annotations in regions around experimentally confirmed genes. Genome-wide TAR predictions were generated in a two-fold cross-validation scheme. Cross-validation accuracy was assessed with respect to annotated genes confirmed by full-length cDNA sequences (Fig. 2B,C) as well as to the modENCODE integrated transcript model (Supplemental Fig. S6; Supplemental Protocols SP16, SP17; Gerstein et al. 2010). 
Additionally, accuracy was compared to modMine TARs (Supplemental Fig. S6; Supplemental Protocol SP17; Supplemental Result SR4).

\section{Identification of new transcripts}

"Unannotated" TARs were identified in comparison to coding and noncoding genes and pseudogenes annotated in WormBase as those with $<20 \mathrm{nt}$ overlap to annotated exons. If additionally a given TAR did not overlap by $\geq 20 \mathrm{nt}$ with exons of the integrated transcript model, we called it a novel transcript (Fig. 2D-F; see Supplemental Protocol SP18). Taking the per-nucleotide union of TARs obtained in individual samples, we obtained nonredundant (nr) TARS (analogously for expressed nrTARs, differentially expressed nrTARs, unannotated nrTARs, and novel nrTARs) (Fig. 2F; see Supplemental Protocol SP18). For each position within expressed nrTARs, we counted the number of samples in which a TAR was detected to generate histograms of sample specificity (Fig. 4C; Supplemental Fig. S17; see Supplemental Protocol SP18).

\section{Detection of expressed transcripts and significant expression differences}

For each annotated protein-coding gene and predicted TAR, we constructed a probe set for expression summarization (see Supplemental Protocol SP19). Subsequently, transcript expression was estimated using a customized RMA pipeline (see Supplemental Protocol SP19; Bolstad et al. 2003; Irizarry et al. 2003; Gautier et al. 2004). A Mann-Whitney U test with an empirical background model and FDR correction for multiple testing was used to detect expressed transcripts (Benjamini and Hochberg 1995). Genes and TARs with an FDR $\leq 0.05$ were reported as expressed above background (see Table 2; Supplemental Fig. S9A; see also Supplemental Protocol SP20). We detected differentially expressed transcripts using a method based on linear models (Smyth 2004). Genes and TARs were called differentially expressed if the FDR was $\leq 0.05$ and the fold change (FC) $\geq 2.0$ (Table 2; Fig. 4A; Supplemental Figs. S9B,C, S12; see Supplemental Protocol SP21). To more strictly correct for potential false-positives resulting from multiple sample comparisons, we divided individual FDR estimates by the number of samples or sample comparisons, respectively. This resulted in an adjusted FDR of $1.3 \times 10^{-4}$ for expression above background and of $7.4 \times 10^{-4}$ for differential expression (Table 2; Supplemental Fig. S12; Supplemental Protocol SP22). We called genes "selectively enriched" in a given tissue (see Results) if they met the following requirements: (1) enriched expression in a given tissue (FDR $\leq$ 0.05 and $\mathrm{FC} \geq 2.0$ ), (2) fold change versus reference among the upper $40 \%$ of the positive FC range observed for this gene across all tissues, and (3) fold-change entropy among the lower $40 \%$ of the distribution observed for all genes (see Supplemental Protocol SP23; Schug et al. 2005).

\section{Self-organizing maps}

We adopted SOMs (Kohonen 1982) as a means of discovering, clustering and visualizing gene expression similarity with respect to cell types or developmental stages. One SOM was fitted to meannormalized $\log _{2}$-transformed gene expression estimates from the developmental stage data set (Fig. 6; Supplemental Fig. S20) and another one to those from cell type samples (Fig. 7; Supplemental Fig. S21; see Supplemental Protocol SP25). Regions in the SOM corresponding to characteristic and coherent expression patterns were afterward identified by $k$-means clustering of the SOM units (with $k=8$ and $k=14$ for the developmental and the cell type data set, respectively) (see Supplemental Protocol SP25). The top half of more coherent SOM units were identified by means of silhouette coefficients resulting in the clusterings shown (Figs. 6, 7; Supplemental Protocol SP25; (Rousseeuw 1987). Finally, we visualized prototypical gene expression patterns for each SOM region. Plotted are genes with a best-matching SOM unit within one of these regions and a quality error below the 50th and 20th percentile for developmental and cell type data sets, respectively (Figs. 6, 7; Supplemental Figs. S20, S22).

\section{Motif discovery}

Regulatory elements were identified using the FIRE algorithm (Elemento et al. 2007). Gene clusters produced from SOM analyses were submitted to the Integrated Genomics Exploration Tools (IGET) website (http://iget.princeton.edu) for analysis using FIRE.

\section{GO/Protein domain enrichment analysis}

Gene lists were tested for gene ontology (GO) or protein domain enrichment using the enrichment widgets on the modMINE website (http://intermine.modencode.org). Significance of enrichment was determined using hypergeometric tests, and $P$-values were corrected for multiple-testing using FDR (Benjamini and Hochberg 1995).

\section{Acknowledgments}

We thank E. Hallem, N. Ringstand, and P. Sternberg for Pgcy33::GFP; B. Grant for Punc-122::RFP; O. Hobert for Prig-3::GFP; Harald Hutter for Pglr-1::dsRed; S. Kim for the Pges-1 mRNA tagging line; P. Roy for the Pmyo-3 mRNA tagging line; D. Marlee and A. George for help with building the Pclh-4 mRNA tagging line; S. Schultheiss for advice with the motif analysis; J. Tap for helpful discussions; D. Anastassiou for support; V. Varadan for advice; G. Seydoux for encouragement; D. Hall and Z. Altun for use of images from WormAtlas; N. Kurn, S. Wang, and J.D. Heath (NuGEN) for help with developing amplification and labeling methods for tiling array hybridization; the Vanderbilt Functional Genomics Shared Resource for microarray processing; and the Veterans Administration Medical Center Flow Cytometry Core and the Vanderbilt University Medical Center Flow Cytometry Core for FACS. Some of the strains used in this work were provided by the C. elegans Genetic Center, which is supported by NIH NCRR. Some GFP expression data were obtained from the Genome BC C. elegans Gene Expression Consortium, which is funded by Genome Canada and Genome British Columbia. This work was supported by the Max Planck Society and DFG RA1894/1-1 (G.R., S.R.H., G.Z.); an EMBL postdoctoral fellowship (G.Z.); NIH grants HG004263 (D.M.M., V.R.), NS49743 (J.D.W.), GM34059 (S.S.), GM83548 (L.P.), R01 NS064273 (S. Shaham), NS26115 (D.M.M.), MH077302 (D.M.M.), and P50 DK44757 (A. Fogo); and NIH grants to Vanderbilt University: P30 CA68485, P60 DK20593, P30 DK58404, HD15052, P30 EY08126, and PO1 HL6744.

\section{References}

Albrecht M, Sharma CM, Reinhardt R, Vogel J, Rudel T. 2010. Deep sequencing-based discovery of the Chlamydia trachomatis transcriptome. Nucleic Acids Res 38: 868-877.

Armour CD, Castle JC, Chen R, Babak T, Loerch P, Jackson S, Shah JK, Dey J, Rohl CA, Johnson JM, et al. 2009. Digital transcriptome profiling using selective hexamer priming for cDNA synthesis. Nat Methods 6: 647-649.

Azzaria M, Goszczynski B, Chung MA, Kalb JM, McGhee JD. 1996. A fork head/HNF-3 homolog expressed in the pharynx and intestine of the Caenorhabditis elegans embryo. Dev Biol 178: 289-303.

Bagga S, Bracht J, Hunter S, Massirer K, Holtz J, Eachus R, Pasquinelli AE. 2005. Regulation by let-7 and lin-4 miRNAs results in target mRNA degradation. Cell 122: 553-563.

Baltus AE, Menke DB, Hu YC, Goodheart ML, Carpenter AE, de Rooij DG, Page DC. 2006. In germ cells of mouse embryonic ovaries, the decision 
to enter meiosis precedes premeiotic DNA replication. Nat Genet 38: 1430-1434.

Barrett T, Troup DB, Wilhite SE, Ledoux P, Rudnev D, Evangelista C, Kim IF, Soboleva A, Tomashevsky M, Marshall KA, et al. 2009. NCBI GEO: Archive for high-throughput functional genomic data. Nucleic Acids Res 37: D885-D890.

Baugh LR, Hill AA, Slonim DK, Brown EL, Hunter CP. 2003. Composition and dynamics of the Caenorhabditis elegans early embryonic transcriptome. Development 130: 889-900.

Benjamini Y, Hochberg Y. 1995. Controlling the false discovery rate: A practical and powerful approach to multiple testing. J R Stat Soc Ser B Methodol 57: 289-300.

Birney E, Stamatoyannopoulos JA, Dutta A, Guigo R, Gingeras TR, Margulies EH, Weng Z, Snyder M, Dermitzakis ET, Thurman RE, et al. 2007. Identification and analysis of functional elements in $1 \%$ of the human genome by the ENCODE pilot project. Nature 447: 799-816.

Blacque OE, Perens EA, Boroevich KA, Inglis PN, Li C, Warner A, Khattra J, Holt RA, Ou G, Mah AK, et al. 2005. Functional genomics of the cilium, a sensory organelle. Curr Biol 15: 935-941.

Bolstad BM, Irizarry RA, Astrand M, Speed TP. 2003. A comparison of normalization methods for high density oligonucleotide array data based on variance and bias. Bioinformatics 19: 185-193.

Bond AM, Vangompel MJ, Sametsky EA, Clark MF, Savage JC, Disterhoft JF, Kohtz JD. 2009. Balanced gene regulation by an embryonic brain ncRNA is critical for adult hippocampal GABA circuitry. Nat Neurosci 12: 10201027

Borevitz JO, Liang D, Plouffe D, Chang H-s, Zhu T, Weigel D, Berry CC, Winzeler E, Chory J. 2003. Large-scale identification of single-feature polymorphisms in complex genomes. Genome Res 13: 513-523.

Bradnam KR, Korf I. 2008. Longer first introns are a general property of eukaryotic gene structure. PLoS ONE 3: e3093. doi: 10.1371/ journal.pone.0003093.

Brenner S. 1974. The genetics of Caenorhabditis elegans. Genetics 77: 71-94.

Budovskaya YV, Wu K, Southworth LK, Jiang M, Tedesco P, Johnson TE, Kim SK. 2008. An elt-3/elt-5/elt-6 GATA transcription circuit guides aging in C. elegans. Cell 134: 291-303.

Calella AM, Nerlov C, Lopez RG, Sciarretta C, von Bohlen und Halbach O, Bereshchenko O, Minichiello L. 2007. Neurotrophin/Trk receptor signaling mediates C/EBPalpha, -beta and NeuroD recruitment to immediate-early gene promoters in neuronal cells and requires C/EBPs to induce immediate-early gene transcription. Neural Develop 2: 4.

Chatzigeorgiou M, Yoo S, Watson JD, Lee WH, Spencer WC, Kindt KS, Hwang SW, Miller DM 3rd, Treinin M, Driscoll M, et al. 2010. Specific roles for DEG/ENaC and TRP channels in touch and thermosensation in C. elegans nociceptors. Nat Neurosci 13: 861-868.

Chen N, Pai S, Zhao Z, Mah A, Newbury R, Johnsen RC, Altun Z, Moerman DG, Baillie DL, Stein LD. 2005. Identification of a nematode chemosensory gene family. Proc Natl Acad Sci 102: 146-151.

Chi W, Reinke V. 2006. Promotion of oogenesis and embryogenesis in the C. elegans gonad by EFL-1/DPL-1 (E2F) does not require LIN-35 (pRB). Development 133: 3147-3157.

Chikina MD, Huttenhower C, Murphy CT, Troyanskaya OG. 2009. Global prediction of tissue-specific gene expression and context-dependent gene networks in Caenorhabditis elegans. PLoS Comput Biol 5: e1000417. doi: 10.1371/journal.pcbi.1000417.

Christensen M, Estevez A, Yin X, Fox R, Morrison R, McDonnell M, Gleason C, Miller DM 3rd, Strange K. 2002. A primary culture system for functional analysis of C. elegans neurons and muscle cells. Neuron 33 503-514.

Cinar H, Keles S, Jin Y. 2005. Expression profiling of GABAergic motor neurons in Caenorhabditis elegans. Curr Biol 15: 340-346.

Colosimo ME, Brown A, Mukhopadhyay S, Gabel C, Lanjuin AE, Samuel AD, Sengupta P. 2004. Identification of thermosensory and olfactory neuron-specific genes via expression profiling of single neuron types. Curr Biol 14: 2245-2251.

del Castillo-Olivares A, Kulkarni M, Smith HE. 2009. Regulation of sperm gene expression by the GATA factor ELT-1. Dev Biol 333: 397-408.

Deshpande G, Calhoun G, Yanowitz JL, Schedl PD. 1999. Novel functions of nanos in downregulating mitosis and transcription during the development of the Drosophila germline. Cell 99: 271-281.

Dupuy D, Bertin N, Hidalgo CA, Venkatesan K, Tu D, Lee D, Rosenberg J, Svrzikapa N, Blanc A, Carnec A, et al. 2007. Genome-scale analysis of in vivo spatiotemporal promoter activity in Caenorhabditis elegans. Nat Biotechnol 25: 663-668.

Elemento O, Slonim N, Tavazoie S. 2007. A universal framework for regulatory element discovery across all genomes and data types. Mol Cell 28: $337-350$.

Fay DS, Stanley HM, Han M, Wood WB. 1999. A Caenorhabditis elegans homologue of hunchback is required for late stages of development but not early embryonic patterning. Dev Biol 205: 240-253.
Flames N, Hobert O. 2009. Gene regulatory logic of dopamine neuron differentiation. Nature 458: 885-889.

Fox RM, Von Stetina SE, Barlow SJ, Shaffer C, Olszewski KL, Moore JH, Dupuy D, Vidal M, Miller DM III. 2005. A gene expression fingerprint of C. elegans embryonic motor neurons. BMC Genomics 6: 42. doi: 10.1186/ gb-2007-8-9-r188.

Fox RM, Watson JD, Von Stetina SE, McDermott J, Brodigan TM, Fukushige T, Krause M, Miller DM III. 2007. The embryonic muscle transcriptome of Caenorhabditis elegans. Genome Biol 8: R188.

Gautier L, Cope L, Bolstad BM, Irizarry Ra. 2004. affy: Analysis of Affymetrix GeneChip data at the probe level. Bioinformatics 20: 307-315.

Gerstein MB, Lu ZJ, Van Nostrand EL, Cheng C, Arshinoff BI, Liu T, Yip KY, Robilotto R, Rechsteiner A, Ikegami K, et al. 2010. Integrative analysis of the Caenorhabditis elegans genome by the modENCODE Project. Science 330: $1775-1787$

Goodyer W, Kaitna S, Couteau F, Ward JD, Boulton SJ, Zetka M. 2008. HTP-3 links DSB formation with homolog pairing and crossing over during C. elegans meiosis. Dev Cell 14: 263-274.

Grange T, Roux J, Rigaud G, Pictet R. 1991. Cell-type specific activity of two glucocorticoid responsive units of rat tyrosine aminotransferase gene is associated with multiple binding sites for C/EBP and a novel liverspecific nuclear factor. Nucleic Acids Res 19: 131-139.

Guo H, Ingolia NT, Weissman JS, Bartel DP. 2010. Mammalian microRNAs predominantly act to decrease target mRNA levels. Nature 466: 835840.

Hall DH, Altun ZF. 2008. C. elegans atlas. Cold Spring Harbor Laboratory Press, Cold Spring Harbor, NY

Hallem EA, Spencer WC, McWhirter RD, Zeller G, Henz SR, Rätsch G, Miller DM III, Horvitz HR, Sternberg PW, Ringstad N. 2010. Receptor-type guanylate cyclase is required for carbon dioxide sensation by Caenorhabditis elegans. Proc Natl Acad Sci 108: 254-259.

He H, Wang J, Liu T, Liu XS, Li T, Wang Y, Qian Z, Zheng H, Zhu X, Wu T, et al. 2007. Mapping the C. elegans noncoding transcriptome with a whole-genome tiling microarray. Genome Res 17: 1471-1477.

Hillier LW, Coulson A, Murray JI, Bao Z, Sulston JE, Waterston RH. 2005. Genomics in C. elegans: So many genes, such a little worm. Genome Res 15: $1651-1660$.

Hillier LW, Reinke V, Green P, Hirst M, Marra MA, Waterston RH. 2009. Massively parallel sequencing of the polyadenylated transcriptome of C. elegans. Genome Res 19: 657-666.

Hirota K, Miyoshi T, Kugou K, Hoffman CS, Shibata T, Ohta K. 2008. Stepwise chromatin remodelling by a cascade of transcription initiation of non-coding RNAs. Nature 456: 130-134.

Hubbard EJA, Greenstein D. 2005. Introduction to the germ line. In WormBook (ed. The C. elegans Research Community, Wormbook) doi: 10.1895/wormbook.1.18.1, http://www.wormbook.org.

Huber W, Toedling J, Steinmetz LM. 2006. Transcript mapping with highdensity oligonucleotide tiling arrays. Bioinformatics 22: 1963-1970.

Hunt-Newbury R, Viveiros R, Johnsen R, Mah A, Anastas D, Fang L, Halfnight E, Lee D, Lin J, Lorch A, et al. 2007. High-throughput in vivo analysis of gene expression in Caenorhabditis elegans. PLoS Biol 5: e237. doi: 10.1371/journal.pbio.0050237.

Hwang SB, Lee J. 2003. Neuron cell type-specific SNAP-25 expression driven by multiple regulatory elements in the nematode Caenorhabditis elegans. J Mol Biol 333: 237-247.

Irizarry RA, Bolstad BM, Collin F, Cope LM, Hobbs B, Speed TP. 2003. Summaries of Affymetrix GeneChip probe level data. Nucleic Acids Res 31: e15. doi: 10.1093/nar/gng015.

Isik M, Korswagen HC, Berezikov E. 2010. Expression patterns of intronic microRNAs in Caenorhabditis elegans. Silence 1: 5. doi: 10.1186/1758907X-1-5.

Jiang M, Ryu J, Kiraly M, Duke K, Reinke V, Kim SK. 2001. Genome-wide analysis of developmental and sex-regulated gene expression profiles in Caenorhabditis elegans. Proc Natl Acad Sci 98: 218-223.

Kato M, de Lencastre A, Pincus Z, Slack FJ. 2009. Dynamic expression of small non-coding RNAs, including novel microRNAs and piRNAs/21URNAs, during Caenorhabditis elegans development. Genome Biol 10: R54. doi: 10.1186/gb-2009-10-5-r54.

Kawasaki I, Shim YH, Kirchner J, Kaminker J, Wood WB, Strome S. 1998. PGL-1, a predicted RNA-binding component of germ granules, is essential for fertility in C. elegans. Cell 94: 635-645.

Kawasaki I, Amiri A, Fan Y, Meyer N, Dunkelbarger S, Motohashi T, Karashima T, Bossinger O, Strome S. 2004. The PGL family proteins associate with germ granules and function redundantly in Caenorhabditis elegans germline development. Genetics 167: 645-661.

Kim SK, Lund J, Kiraly M, Duke K, Jiang M, Stuart JM, Eizinger A, Wylie BN, Davidson GS. 2001. A gene expression map for Caenorhabditis elegans. Science 293: 2087-2092.

Kimble J. 1981. Alterations in cell lineage following laser ablation of cells in the somatic gonad of Caenorhabditis elegans. Dev Biol 87: 286300 . 
Kimble J, Crittenden SL. 2005. Germline proliferation and its control. In WormBook (ed. The C. elegans Research Community, Wormbook) doi: 10.1895/wormbook.1.13.1, http://www.wormbook.org.

Koh K, Rothman JH. 2001. ELT-5 and ELT-6 are required continuously to regulate epidermal seam cell differentiation and cell fusion in C. elegans. Development 128: 2867-2880.

Kohonen T. 1982. Self-organized formation of topologically correct feature maps. Biol Cybern 43: 59-69.

Krause M, Park M, Zhang JM, Yuan J, Harfe B, Xu SQ, Greenwald I, Cole M, Paterson B, Fire A. 1997. A C. elegans E/Daughterless bHLH protein marks neuronal but not striated muscle development. Development 124: 21792189.

Laubinger S, Zeller G, Henz SR, Sachsenberg T, Widmer CK, Naouar N, Vuylsteke M, Scholkopf B, Rätsch G, Weigel D. 2008. At-TAX: A whole genome tiling array resource for developmental expression analysis and transcript identification in Arabidopsis thaliana. Genome Biol 9: R112. doi: $10.1186 / \mathrm{gb}-2008-9-7-\mathrm{r} 112$.

Li X, Panea C, Wiggins CH, Reinke V, Leslie C. 2010. Learning "graph-mer" motifs that predict gene expression trajectories in development. PLoS Comput Biol 6: e1000761. doi: 10.1371/journal.pcbi.1000761.

Lim LP, Lau NC, Weinstein EG, Abdelhakim A, Yekta S, Rhoades MW, Burge CB, Bartel DP. 2003. The microRNAs of Caenorhabditis elegans. Genes Dev 17: $991-1008$

Liu X, Long F, Peng H, Aerni SJ, Jiang M, Sanchez-Blanco A, Murray JI, Preston E, Mericle B, Batzoglou S, et al. 2009. Analysis of cell fate from single-cell gene expression profiles in C. elegans. Cell 139: 623633.

Lu ZJ, Yip KY, Wang G, Shou C, Hillier LW, Khurana E, Agarwal A, Auerbach $\mathrm{R}$, Rozowsky J, Cheng C, et al. 2011. Prediction and characterization of non-coding RNAs in C. elegans by integrating conservation, secondary structure and high throughput sequencing and array data. Genome Res (this issue). doi: 10.1101/gr.110189.110.

Martinez NJ, Ow MC, Reece-Hoyes JS, Barrasa MI, Ambros VR, Walhout AJ. 2008. Genome-scale spatiotemporal analysis of Caenorhabditis elegans microRNA promoter activity. Genome Res 18: 2005-2015.

McGhee JD, Sleumer MC, Bilenky M, Wong K, McKay SJ, Goszczynski B, Tian H, Krich ND, Khattra J, Holt RA, et al. 2007. The ELT-2 GATA-factor and the global regulation of transcription in the C. elegans intestine. Dev Biol 302: 627-645.

McGhee JD, Fukushige T, Krause MW, Minnema SE, Goszczynski B, Gaudet J, Kohara Y, Bossinger O, Zhao Y, Khattra J, et al. 2009. ELT-2 is the predominant transcription factor controlling differentiation and function of the C. elegans intestine, from embryo to adult. Dev Biol 327: $551-565$.

McKay SJ, Johnsen R, Khattra J, Asano J, Baillie DL, Chan S, Dube N, Fang L, Goszczynski B, Ha E, et al. 2003. Gene expression profiling of cells, tissues, and developmental stages of the nematode C. elegans. Cold Spring Harb Symp Quant Biol 68: 159-169.

Meissner B, Warner A, Wong K, Dube N, Lorch A, McKay SJ, Khattra J, Rogalski T, Somasiri A, Chaudhry I, et al. 2009. An integrated strategy to study muscle development and myofilament structure in Caenorhabditis elegans. PLoS Genet 5: e1000537. doi: 10.1371/journal.pgen.1000537.

Mercer TR, Dinger ME, Sunkin SM, Mehler MF, Mattick JS. 2008. Specific expression of long noncoding RNAs in the mouse brain. Proc Natl Acad Sci 105: 716-721.

Mukai M, Kitadate Y, Arita K, Shigenobu S, Kobayashi S. 2006. Expression of meiotic genes in the germline progenitors of Drosophila embryos. Gene Expr Patterns 6: 256-266.

Murray JI, Bao Z, Boyle TJ, Boeck ME, Mericle BL, Nicholas TJ, Zhao Z, Sandel MJ, Waterston RH. 2008. Automated analysis of embryonic gene expression with cellular resolution in C. elegans. Nat Methods 5: 703 709 .

Okkema PG, Harrison SW, Plunger V, Aryana A, Fire A. 1993. Sequence requirements for myosin gene expression and regulation in Caenorhabditis elegans. Genetics 135: 385-404.

Ow MC, Martinez NJ, Olsen PH, Silverman HS, Barrasa MI, Conradt B, Walhout AJ, Ambros V. 2008. The FLYWCH transcription factors FLH-1, FLH-2, and FLH-3 repress embryonic expression of microRNA genes in C. elegans. Genes Dev 22: 2520-2534.

Pasierbek P, Jantsch M, Melcher M, Schleiffer A, Schweizer D, Loidl J. 2001. A Caenorhabditis elegans cohesion protein with functions in meiotic chromosome pairing and disjunction. Genes Dev 15: 1349-1360.

Pauli F, Liu Y, Kim YA, Chen PJ, Kim SK. 2006. Chromosomal clustering and GATA transcriptional regulation of intestine-expressed genes in C. elegans. Development 133: 287-295.

Reinke V, Smith HE, Nance J, Wang J, Van Doren C, Begley R, Jones SJ, Davis $\mathrm{EB}$, Scherer S, Ward S, et al. 2000. A global profile of germline gene expression in C. elegans. Mol Cell 6: 605-616.

Reinke V, Gil IS, Ward S, Kazmer K. 2004. Genome-wide germline-enriched and sex-biased expression profiles in Caenorhabditis elegans. Development 131: $311-323$
Reynolds NK, Schade MA, Miller KG. 2005. Convergent, RIC-8-dependent Galpha signaling pathways in the Caenorhabditis elegans synaptic signaling network. Genetics 169: 651-670.

Rinn JL, Kertesz M, Wang JK, Squazzo SL, Xu X, Brugmann SA, Goodnough LH, Helms JA, Farnham PJ, Segal E, et al. 2007. Functional demarcation of active and silent chromatin domains in human HOX loci by noncoding RNAs. Cell 129: 1311-1323.

Rogers A, Antoshechkin I, Bieri T, Blasiar D, Bastiani C, Canaran P, Chan J, Chen WJ, Davis P, Fernandes J, et al. 2008. WormBase 2007. Nucleic Acids Res 36: D612-D617.

Rousseeuw P. 1987. Silhouettes: A graphical aid to the interpretation and validation of cluster analysis. J Comput Appl Math 20: 53-65.

Roy PJ, Stuart JM, Lund J, Kim SK. 2002. Chromosomal clustering of muscleexpressed genes in Caenorhabditis elegans. Nature 418: 975-979.

Ruby JG, Jan C, Player C, Axtell MJ, Lee W, Nusbaum C, Ge H, Bartel DP. 2006. Large-scale sequencing reveals $21 \mathrm{U}$-RNAs and additional microRNAs and endogenous siRNAs in C. elegans. Cell 127: 11931207.

Sandelin A, Alkema W, Engstrom P, Wasserman WW, Lenhard B. 2004. JASPAR: an open-access database for eukaryotic transcription factor binding profiles. Nucleic Acids Res 32: D91-D94.

Schug J, Schuller WP, Kappen C, Salbaum JM, Bucan M, Stoeckert CJ Jr. 2005. Promoter features related to tissue specificity as measured by Shannon entropy. Genome Biol 6: R33. doi: 10.1186/gb-2005-6-4-r33.

Schweikert G, Zien A, Zeller G, Behr J, Dieterich C, Ong CS, Philips P, De Bona F, Hartmann L, Bohlen A, et al. 2009. mGene: Accurate SVM-based gene finding with an application to nematode genomes. Genome Res 19: 2133-2143.

Shakes DC, Wu JC, Sadler PL, Laprade K, Moore LL, Noritake A, Chu DS 2009. Spermatogenesis-specific features of the meiotic program in Caenorhabditis elegans. PLoS Genet 5: e1000611. doi: 10.1371/ journal.pgen.1000611.

Smith CJ, Watson JD, Spencer WC, O'Brien T, Cha B, Albeg A, Treinin M, Miller DM 3rd. 2010. Time-lapse imaging and cell-specific expression profiling reveal dynamic branching and molecular determinants of a multi-dendritic nociceptor in C. elegans. Dev Biol 345: $18-33$.

Smyth, G.K. 2004. Linear models and empirical bayes methods for assessing differential expression in microarray experiments. Stat Appl Genet Mol Biol 3: Article3. doi: 10.2202/1544-6115.1027.

Strome S, Wood WB. 1983. Generation of asymmetry and segregation of germ-line granules in early C. elegans embryos. Cell 35: 15-25.

Subramaniam K, Seydoux G. 1999. nos-1 and nos-2, two genes related to Drosophila nanos, regulate primordial germ cell development and survival in Caenorhabditis elegans. Development 126: 4861-4871.

Sulston JE, Horvitz HR. 1977. Post-embryonic cell lineages of the nematode, Caenorhabditis elegans. Dev Biol 56: 110-156.

Sulston JE, Schierenberg E, White JG, Thomson JN. 1983. The embryonic cell lineage of the nematode Caenorhabditis elegans. Dev Biol 100: 64-119.

Thellmann M, Hatzold J, Conradt B. 2003. The Snail-like CES-1 protein of C. elegans can block the expression of the BH3-only cell-death activator gene egl-1 by antagonizing the function of bHLH proteins. Development 130: $4057-4071$.

Touroutine D, Fox RM, Von Stetina SE, Burdina A, Miller DM 3rd, Richmond JE. 2005. acr-16 encodes an essential subunit of the levamisole-resistant nicotinic receptor at the Caenorhabditis elegans neuromuscular junction. J Biol Chem 280: 27013-27021.

Troemel ER, Chou JH, Dwyer ND, Colbert HA, Bargmann CI. 1995. Divergent seven transmembrane receptors are candidate chemosensory receptors in C. elegans. Cell 83: 207-218.

Tsai MC, Manor O, Wan Y, Mosammaparast N, Wang JK, Lan F, Shi Y, Segal E, Chang HY. 2010. Long noncoding RNA as modular scaffold of histone modification complexes. Science 329: 689-693.

van Bakel H, Nislow C, Blencowe BJ, Hughes TR. 2010. Most "dark matter" transcripts are associated with known genes. PLoS Biol 8: e1000371. doi: 10.1371/journal.pbio.1000371.

Von Stetina SE, Watson JD, Fox RM, Olszewski KL, Spencer WC, Roy PJ, Miller DM 3rd. 2007. Cell-specific microarray profiling experiments reveal a comprehensive picture of gene expression in the C. elegans nervous system. Genome Biol 8: R135. doi: 10.1186/gb-2007-8-7-r135.

Wang X, Zhao Y, Wong K, Ehlers P, Kohara Y, Jones SJ, Marra MA, Holt RA, Moerman DG, Hansen D. 2009. Identification of genes expressed in the hermaphrodite germ line of C. elegans using SAGE. BMC Genomics 10: 213. doi: $10.1186 / 1471-2164-10-213$

Wilusz JE, Sunwoo H, Spector DL. 2009. Long noncoding RNAs: Functional surprises from the RNA world. Genes Dev 23: 1494-1504.

Yang Y, Xu S, Xia L, Wang J, Wen S, Jin P, Chen D. 2009. The bantam microRNA is associated with Drosophila fragile X mental retardation protein and regulates the fate of germline stem cells. PLoS Genet 5: e1000444. doi: 10.1371/journal.pgen.1000444.

\section{Genome Research}


You FM, Huo N, Gu YQ, Luo MC, Ma Y, Hane D, Lazo GR, Dvorak J, Anderson OD. 2008. BatchPrimer3: A high throughput web application for PCR and sequencing primer design. BMC Bioinformatics 9: 253. doi: 10.1186/1471-2105-9-253.

Zeller G, Henz SR, Laubinger S, Weigel D, Rätsch G. 2008. Transcript normalization and segmentation of tiling array data. Pac Symp Biocomput 2008:527-538.

Zeller G, Henz SR, Widmer CK, Sachsenberg T, Rätsch G, Weigel D, Laubinger S. 2009. Stress-induced changes in the Arabidopsis thaliana transcriptome analyzed using whole-genome tiling arrays. Plant J 58:1068-1082.

Zhang Y, Ma C, Delohery T, Nasipak B, Foat BC, Bounoutas A, Bussemaker HJ, Kim SK, Chalfie M. 2002. Identification of genes expressed in C. elegans touch receptor neurons. Nature 418: 331-335.

Received September 3, 2010; accepted in revised form December 8, 2010. 


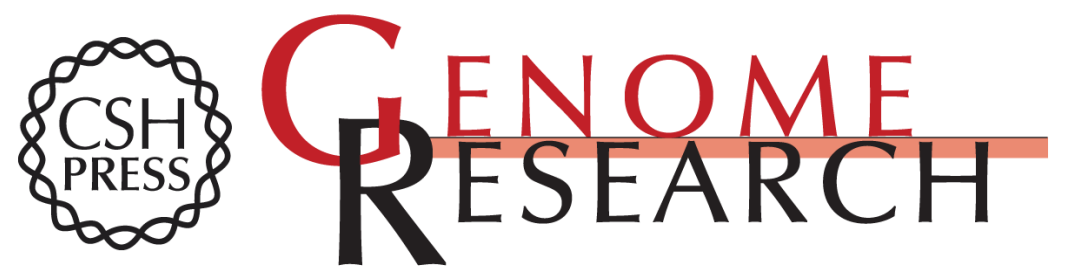

\section{A spatial and temporal map of $C$. elegans gene expression}

W. Clay Spencer, Georg Zeller, Joseph D. Watson, et al.

Genome Res. 2011 21: 325-341 originally published online December 22, 2010

Access the most recent version at doi:10.1101/gr.114595.110

Supplemental
Material http://genome.cshlp.org/content/suppl/2010/12/20/gr.114595.110.DC1

Related Content High nucleosome occupancy is encoded at X-linked gene promoters in C. elegans

Sevinç Ercan, Yaniv Lubling, Eran Segal, et al.

Genome Res. February , 2011 21: 237-244 Multimodal RNA-seq using

single-strand, double-strand, and CircLigase-based capture yields a refined and extended description of the $\mathrm{C}$. elegans transcriptome

Ayelet T. Lamm, Michael R. Stadler, Huibin Zhang, et al.

Genome Res. February, 2011 21:265-275 Genome-wide analysis of alternative splicing in Caenorhabditis elegans

Arun K. Ramani, John A. Calarco, Qun Pan, et al.

Genome Res. February , 2011 21: 342-348 A global analysis of C. elegans trans-splicing

Mary Ann Allen, LaDeana W. Hillier, Robert $\mathrm{H}$. Waterston, et al.

Genome Res. February , $201121: 255-264$ Prediction and characterization of

noncoding RNAs in C. elegans by integrating conservation, secondary

structure, and high-throughput sequencing and array data

Zhi John Lu, Kevin Y. Yip, Guilin Wang, et al.

Genome Res. February, 2011 21:276-285 Computational and experimental

identification of mirtrons in Drosophila melanogaster and Caenorhabditis

elegans

Wei-Jen Chung, Phaedra Agius, Jakub O. Westholm, et al.

Genome Res. February , 2011 21: 286-300 Broad chromosomal domains of

histone modification patterns in C. elegans

Tao Liu, Andreas Rechtsteiner, Thea A. Egelhofer, et al.

Genome Res. February , 2011 21:227-236 Diverse transcription factor binding

features revealed by genome-wide ChIP-seq in C. elegans

Wei Niu, Zhi John Lu, Mei Zhong, et al.

Genome Res. February , 2011 21:245-254

\section{Affordable, Accurate Sequencing.}

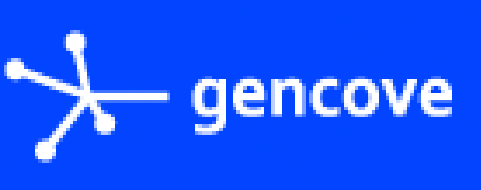

To subscribe to Genome Research go to:

https://genome.cshlp.org/subscriptions 
References This article cites 102 articles, 26 of which can be accessed free at: http://genome.cshlp.org/content/21/2/325.full.html\#ref-list-1

Articles cited in:

http://genome.cshlp.org/content/21/2/325.full.html\#related-urls

Open Access Freely available online through the Genome Research Open Access option.

License Freely available online through the Genome Research Open Access option.

Email Alerting Receive free email alerts when new articles cite this article - sign up in the box at the Service top right corner of the article or click here.

\section{Affordable, Accurate} Sequencing.

To subscribe to Genome Research go to:

https://genome.cshlp.org/subscriptions 